\title{
Breeding for FHB Resistance via Fusarium Damaged Kernels and Deoxynivalenol Accumulation as Well as Inoculation Methods in Winter Wheat
}

\author{
Akos Mesterházy ${ }^{*}$, Szabolcs Lehoczki-Krsjak ${ }^{1}$, Mónika Varga ${ }^{1}$, Ágnes Szabó-Hevér1, \\ Beata Tóth ${ }^{1}$, Marc Lemmens ${ }^{2}$ \\ ${ }^{1}$ Cereal Research Non-Profit Ltd, Szeged, Hungary \\ ${ }^{2}$ University of Life Sciences-BOKU, IFA, Tulln, Austria \\ Email: ${ }^{*}$ akos.mesterhazy@gabonakutato.hu
}

Received 18 August 2015; accepted 18 September 2015; published 22 September 2015

Copyright (C) 2015 by authors and Scientific Research Publishing Inc.

This work is licensed under the Creative Commons Attribution International License (CC BY). http://creativecommons.org/licenses/by/4.0/

(c) (i) Open Access

\section{Abstract}

FHB is one of the most destructive diseases of wheat. Resistance testing depends strongly on inoculation methods, and on measured traits. Therefore a four-year (2009-2012) study was performed using spray inoculation + polyethylene (PE) bag cover, spray inoculation + mist irrigation, and spawn method supported by mist irrigation on 40 genotypes, 20 from Hungary and 20 from IFA Tulln, Austria. Each year four isolates were used in artificial inoculations except the spawn method where stalk debris served the inoculum. Visual Fusarium head blight (FHB) scores, Fusarium damaged kernels (FDK) and deoxynivalenol (DON) contamination were checked. 7680 FHB and FDK, as well as 3840 DON analyses served as the background for the statistical evaluation. The most reliable method used was the spray + polyethylene (PE) bag; the other two were significantly poorer being valid for all traits. The FHB scores were the least reliable, whereas the FDK was much more consequent and the DON gave the best results. The FDK gave much better predictions for DON contamination than FHB. The cultivars responses correlated well at different epidemic severities. The presence of the kernel resistance was confirmed and a new trait as extra kernel susceptibility was described. Presence of DON resistance was confirmed again, and extra DON susceptibility was described as a new trait. DON performance varied on the most sensitive cultivar between 0.32 and $143 \mathrm{mg} / \mathrm{kg}$ (mean $17.52 \mathrm{mg} / \mathrm{kg}$ ) and on the most resistant genotype between 0.00 and $18.19 \mathrm{mg} / \mathrm{kg}$ (mean 1.87 $\mathrm{mg} / \mathrm{kg}$ ). Correlations between stability and resistance level are $\mathrm{r}=0.85$ for FHB, 0.78 for FDK, and 0.88 for DON, all at a significance level of $p=0.001$. The very close correlation between FDK and DON contamination $(r=0.81, p=0.001)$ proves that control of DON contamination needs appropriate resistance. In the breeding program evaluation of FDK is the most important, and then DON will be decided. Variety registration must be updated; otherwise no improvement on the field will occur.

*Corresponding author.

How to cite this paper: Mesterházy, A., Lehoczki-Krsjak, S., Varga, M., Szabó-Hevér, Á., Tóth, B. and Lemmens, M. (2015) Breeding for FHB Resistance via Fusarium Damaged Kernels and Deoxynivalenol Accumulation as Well as Inoculation Methods in Winter Wheat. Agricultural Sciences, 6, 970-1002. http://dx.doi.org/10.4236/as.2015.69094 


\section{Keywords}

FHB Resistance, Kernel Resistance, Kernel Susceptibility, DON Resistance, DON Susceptibility,
Inoculation Techniques, Breeding Aspects Component, Formatting, Style, Styling

\section{Introduction}

Fusarium head blight (FHB) is an economically devastating disease of wheat and other small grains [1]-[4]. The quality and yield loss might be significant, but the losses caused by toxins are economically more important. As chemical protection, in spite of its progress [5]-[10], has only a moderate effect, the necessity of breeding more resistant wheat cultivars is inevitable. It is generally assumed that breeding for resistance against Fusarium head blight (FHB) is the most effective method to decrease DON contamination. The practical results are, however, not so good as expected. For this reason the problem needs a careful revision and we should clarify several aspects that we did not consider to have a serious importance. Climate change increases the chances of FHB epidemics in many wheat producing areas, which is also an argument for significantly increasing resistance [11]. Wheat is damaged by many Fusarium spp. worldwide, but the main pathogen near everywhere is F. graminearum (Gibberella zeae) or F. culmorum. For this reason we concentrate on these species as they are responsible for the DON contamination of the cereal grains we want to lower.

Genetic studies underline the complexity of the resistance. The rare QTL analyses by testing all traits (FHB, FDK, DON) clearly show that some QTLs determine resistance to FHB, FDK or DON, or their combination [12]-[14]. The validation of the QTLs has not always been successful, for example, the Arina studies showed a high number of QTLs in three different populations, but only the QTL for the Rht-D1 gene co-localizing with a Fusarium QTL was shown to be common [15]-[17]. This draws attention to the complexity of the genetic background for the small and intermediately strong QTLs which exhibit many different heretofore unknown regulatory mechanisms. The non-specific nature of the 3BS and 5AS FHB qtls (fhb1, Qfhs.ifa-5A) [12] [18]-[20] was described by Mesterházy et al. [21], showing that these large-effect QTLs confer protection against both Type I and Type II resistances simultaneously with spraying inoculation. However, when only one of them is present, only a medium-sized resistance is found. The QTLs allow a medium- sized resistance only. Most sources report that Type II resistance is incomplete, full resistance or immunity has not been found [12]. Its methodical background clearly described the single floret inoculation, therefore most people preferred to use this method. Type I resistance is treated as a mysterious factor and the mechanism behind Type I resistance is not well known, therefore neglected. It is also incomplete as Type II. The progress based on studying the 3BS (fhb1) QTL was much slower than expected. The reason is that Type I resistance determined by the 5A QTL is about as strong as Type II fhb1 QTL on 3BS from CM82036 (descended form Sumai 3) and their common effect secures the high resistance in Sumai 3 [21]. This is called transgenic segregation. Liu and Wang [22] analyzed this for FHB in wheat and numerous more resistant plants were identified from corsses than the more resistant parent was. This means that acting alone these QTLs determine only an intermediate-level of resistance. The fhb1 marker can only follow Type II resistance, and so the higher plant resistance is thought to be conferred by Type II resistance. In reality, many of the marker-selected plants for 3BS have medium resistance as the 5A Type 1 QTL resistance has not been present in them. Another problem is that resistance evaluation concentrates on the visual head symptoms. Most of the QTL analyses chose this trait [12] [23]. The FDK and DON were generally neglected in the first 10 - 15 years. Mesterházy [24] and Mesterházy et al. [25] draw attention to the fact that there was no automatic correspondence between the expression of resistance by different traits; even the correlations between them were normally close.

Bai et al. [26] were among the first that considered also FDK and DON inheritance. They introduced the additional resistance types, such as resistance to kernel infection and resistance to DON. Therefore, we have to analyze the responses of genotypes to different traits as it might have serious impact on our breeding methods.

In FHB resistance many papers speak about resistance to DON. This seems, therefore, to be a synonym for the resistance to the disease. However, a careful analysis is not made. We know that the DON-glycoside production of $f h b 1$ plants detoxifies DON. Thus, due to lower DON production, the plants will show higher resistance [27] as DON is an aggressiveness factor for the fungal spread after infection. DON production may be low as the infection severity is also low. Kernels which are less infected by disease also mean less toxin, and that other 
DON decomposing or inhibiting mechanisms might also be present [27]-[31]. As many papers did not find close correlations between DON and disease severity, this problem should also be analyzed. In our results the correlations between FHB, FDK and DON are generally close, but higher in tests lasting more years ( $\mathrm{r}=0.80$, sometimes higher) [7] [24] [25] [32] [33], but the correlations between FDK and DON were closer than between FHB and DON. Bai et al. [26] also supported these findings. Since we concentrated earlier on studying resistance characteristics, we did not pay enough attention to DON overproduction, which also had food safety aspects. Therefore, this aspect should also have been analyzed.

We had to consider several factors when choosing which method to apply. Spray inoculation was considered in order to measure only Type I resistance. It became clear that it measured the overall resistance as the total effect of QTLs with Type I and Type II resistance components Zwart et al. [34]. The natural-close spawn method also belongs to this group of inoculation methods [35]. Since the spawn method is described widely in the literature, especially in breeding, this is the first method we chose. The method is simple, highly productive, but not very precise. We cannot determine the inoculation time, therefore the rating of the disease is imprecise, and furthermore many different age infections develop on the side. However, as Bai et al. [26] used it successfully, this supported the idea to include this method into the program. The spray method was described as the Type I method [36], irrespective of whether the humidity was provided by bags or irrigation. A version of spraying inoculation was developed by Mesterházy [1] that is more laborious than others are. However, inoculation time and disease development can be described more precisely. The $48 \mathrm{hr}$ coverage by polyethylene bags ensured the length of humid period necessary to initiate the epidemic level [6]. Of course, natural rains can cause problems by unevenly moisturizing different ripening groups. The spray inoculation method combined with misting [37]-[39] was developed in Austria, but a version of it used by Miedaner [40] is also used in breeding. The Lemmens et al. [27] version of the method is simpler to apply during a methodical study, so we used this version. As methods may interact with resistance ranking, the usefulness and applicability of the methods should be compared. Lemmens et al. [27] compared four inoculation methods on ten winter wheat genotypes in two years and in two locations, where 1) conidial suspension was sprayed on heads and humidity was secured by polyethylene bags for 24 hrs.; 2) the same method, but PE coverage lasted 18 hrs. 3) the same spray inoculation (one F. culmorum isolate) in the evening without bag cover; and 4) a similar inoculation, but inoculation was repeated two days later. The four methods were used without and with mist irrigation. In the test visual symptoms (FHB) and DON were evaluated. AUDPC values measured between different methodical approaches were highly correlated $(r=0.85$ - 0.95). The visual symptoms and DON correlated well only at lower epidemic severity, but at high infection severity no useful correlation was found. Mist irrigation increased DON contamination. Natural excess rains have the same effect [6], where the wet parts of the year 2008 increased the DON contamination nearly tenfold compared to the previous year at relatively low FHB and FDK values. We found that the number of isolates should increase, and that the number of genotypes and FDK should also be included. The length of the mist irrigation is also important from the practical observation that a high epidemic needs long lasting humid period. The lessons learned from this test were seriously considered in the planning of the subsequent test series.

The single floret injecting method that also employed combined with PR bag coverage for 24 hrs [41] was not used in our tests for two reasons. As the genetic background is different for the two traits [12] [36], the presence or absence of the significant correlation is not decisive for the comparison. Jin et al. [42] found a reasonable good correlation between visuals symptoms of single floret and spraying inoculation on 363 wheat lines, in other tests the correlations varied between $r=0.45-0.64(p=0.001)$. This might have significance for breeding, but the diverging genetic background and their different methodical approaches remain a problem.

Epidemic severity influences variety ranking. This is clear from many papers presenting data from different years or locations. The problem is that the epidemic severity effect is combined with year and location effects. Therefore their separation would be necessary. In the inoculation methodology we have been using for 40 years four isolates were discovered which show different levels of aggressiveness [7] [24] [43] [44]. Earlier we looked at the isolate specific data to see the reproducibility of the aggressiveness in different years, since it was mentioned in the publications. In all of the tests large deviations were found. In this test series we ranked the isolates according to their average FHB values by year. We also grouped the FDK and DON data accordingly. This way it becomes possible to see the effect of aggressiveness on the resistance expression. The parallel use of isolates is not customary. It is true that there is no race specificity in the F. graminearum and other Fusarium species [45], but we observed that in each test the results of the variety ranking are similar, and in several cases large deviations can be observed. To improve the data, more isolates (four) were used, resulting in better data quality 
as the reaction difference to the four isolates does not contain environmental interaction. The 3 - 4 year testing therefore gives reliable information. This methodology is therefore suitable to answer scientific question that otherwise cannot be analyzed.

The genetic variability in European material has been described [37] [46], and many land races and breeding materials were identified which have a reasonable level of resistance. Brown-Gudeira et al. [47] define them as native resistance sources. Their characterization would be very important and this would significantly contribute to the success of breeding technologies.

The problem is up-to-date as in breeding work where mainly the FHB visual symptoms are rated [48], even they admit that low DON contamination is also a breeding goal. It is clear that the transformation of the scientific results into the breeding praxis is slow. With this work we would like to enhance this activity that needs much more effort as generally supposed.

The main objectives of the study are: 1) to compare artificial inoculation methods to determine the optimal method of identifying the resistance level of the wheat genotypes to FHB; 2) to better understand the complicated relationship between FHB, FDK and DON and their significance for resistance testing including variety registration. 3) to study how the epidemic severity influences variety ranking and resistance expression; 4) to develop more efficient selection schemata to breed wheat cultivars with higher resistance to FHB; 5) to consider food safety aspects of DON overproduction and how to control it.

\section{Materials and Methods}

\subsection{Experimental Design}

The test was run during the period 2009-2012 in the Plant Breeding Station of Cereal Research Company in Szeged. The previous crop was all year's oil rape. The location of experimental fields [9] is several hundred meters from the GPS coordinates: $46^{\circ} 11^{\prime} 42.15^{\prime \prime} ; 0^{\circ} 8^{\prime} 56.13^{\prime \prime}$. The field is in the Tisza river valley, it is alluvial with medium to high clay content, and has high humus content (3\% - 4\%), and a deep production depth of about $1 \mathrm{~m}$ with excellent water economy. The experimental field was eight ha, in the middle a road that divided it into two parts side by side, where wheat and oil rape alternated. The soil was fertilized at $60+60+60 \mathrm{~kg}$ a.i. for NPK (nitrogen, phosphorus, potassium) in the autumn before plowing [mid-September) and an additional $60 \mathrm{~kg}$ $\mathrm{N}$ was added at the beginning of April. The yield of grain each year also depends on the amount of rainfall, with the yearly means of grain between 4 and 10 t/ha. Sowing time was in the middle of October with a difference of several days between years, which was the optimal sowing time. The seeds were sown by Rowseed TC single rod seed machine from Wintersteiger GmbH, Ried, Austria.

In the artificially inoculated plots with two row plots were used, the row spacing was $20 \mathrm{~cm}$, and the plot length was $1.8 \mathrm{~m}$. For the spawn method plots of three rows were sown. All tests were replicated twice, in a randomized factorial block design (e.g. two plots per treatment). In one plot two groups of heads were inoculated with the same isolate, together 8 groups of heads were treated with the four isolates. the two factorial replicates within the same plot were averaged, and so two replicates from the two plots were the entries into the statistical analysis.

The years 2009, 2011, and 2012 were dry to very dry, with a May-June precipitation of 40 - $50 \mathrm{~mm}$, but 2010 was extra wet with $290 \mathrm{~mm}$ precipitation in the same period. 2009 was hot in the inoculation period, 2011 and 2012 were rather cool with $18^{\circ} \mathrm{C}-20^{\circ} \mathrm{C}$ daily maximums for one week-10 days.

\subsection{Plant Material}

20 Hungarian and 20 Austrian winter wheat heat genotypes were selected for the experiment considering a wide variability in resistance. As the only trait for selection was to provide a high variability, the other traits were not tested like quality, yielding ability etc. In the Hungarian genotypes earlier tests were considered from the very susceptible to highly resistant. The Austrian genotypes were selected based on earlier experimental data. The Hungarian materials were about 5 - 7 days earlier than the Austrian ones, however the two inoculation dates we applied gave similar results, except several highly resistant materials from the Hungarian breeding program. The name of the cultivars is printed in Table 2 etc. From the tables it is clear that the cultivars and lines had a large variability for FHB resistance, e.g. they represented a large variability that allowed to compare behavior of cultivars for resistance and their stability under different epidemic conditions. Otherwise the combination or the 
experimental entry number is given. Generally the Hungarian genotypes were earlier flowering, the Austrian were about one week later. The higher number of genotypes was necessary as sound conclusions can seldom be made based on a low number of genotypes.

\subsection{Inoculum Production}

The origin of the isolates (Table 1) is: F. graminearum: No. 12377 (from maize seed; Vésztő, Hungary, 1978), No. 46.06, [wheat grain, Kiszombor, Hungary), No. 13.05 (wheat grain Kiszombor, 2005), F. culmorum No. 12375 (wheat root; Szeged, Hungary, 1978) and No. 12551 (wheat stalk base; Szeged, Hungary, 1978) and No. 89.4 (INRA Rennes, France, 1986). All are of DON type; however 89.4 can also produce nivalenol. The F. graminearum isolates belonged to the $F$. graminearum strict senso of the F. graminearum species complex. The isolates were monosporic, and were stored in a freezer at $-80^{\circ} \mathrm{C}$.

Inocula were produced by the bubble breeding method in $10 \mathrm{~L}$ heat stable glass balloons [1] [6]. After one week of aeration the suspension was checked for aggressiveness at original concentration and dilutions with ion changed water at 1:1, 1:2 and 1:4 dilution ratios [53]. The test results suggested us to use or discard the given inoculum. The seedling tests and head tests showed most cases close results and founded this way of doing [49]. The inocula were kept until use in a refrigerator at $4{ }^{\circ} \mathrm{C}$. The isolates were monosporic, and were stored in a refrigerator at $-80^{\circ} \mathrm{C}$. Inocula contained amixture of mycelium and conidia. As the flowering period was about 10 days long with some differences in the years tested, only such an amount was taken out from the inoculum that was necessary for the given day, while the rest was kept in the refrigerator. This way the identity of the inoculum and its aggressiveness could be kept stable at the original aggressiveness level. As surprises seldom occurred, at the end of the inoculation period the rest of the suspensions were tested again to check aggressiveness. In this test no loss of aggressiveness was found, so the data could be used for evaluation.

\subsection{Inoculation}

Inoculation was performed accordingly at the full flowering stage (Feekes scale 10.51). This is the most sensitive phase of the plant, and therefore chosen as the time of the inoculations [1] [50] [51] independently which inoculation method is used. They all have different variants in their methodology, some art of spraying, the point inoculation and the spawn method. Since FHB pathogens are not specialized [24] [33] [44] [45] [52], most researchers use single isolates or a mixture of isolates to balance possible variation between isolates [35] [51]. We have found that the aggressiveness of a given isolate varies strongly from year to year [6] [24] [25] [33]. Prediction based on conidium concentration was not possible except when the same inoculum was diluted. The results were rather different, even showing a reduction in values [43]. For this reason the aggressiveness test and not the conidium concentration was used [43] [53] to decide whether to use a specific inoculum or not. Since resistance expression depends also on the level of aggressiveness, the mean values of more epidemics generated from the mean of several independently used isolates (inocula) always gives more precise information on the level of resistance than a single isolate with its more or less accidental aggressiveness level or a mixture that represents only one aggressiveness level. The more epidemic time periods modeled by the use of more (in our praxis four) isolates, has proved their scientific value (more exact phenotyping for mapping populations and resistance screening of genotypes). So it was useful both in practical field work and also in genetic research. Since no environmental interaction was found between epidemics caused by different isolates (the same conditions applied for all treatments), the influence of aggressiveness differences could be studied much more precisely than with a mixture of isolates where values were observed for only one aggressiveness level.

Table 1. Isolates used in the 2009-2012 experimental period.

\begin{tabular}{ccccc}
\hline \multirow{2}{*}{$\begin{array}{c}\text { Epidemic } \\
\text { severity }\end{array}$} & \multicolumn{3}{c}{ Years } & 2012 \\
\cline { 2 - 5 } & 2009 & 2010 & 2011 & Fg 12377 \\
Low & Fc 12551 & Fc 12551 & Fc 12551 & Fg 46.06 \\
Medium & Fg 12377 & Fg 46.06 & Fc 12375 & Fg 13.05 \\
High & Fc 89.4 & Fc 12375 & Fg 12377 & Fc 12375 \\
Very high & Fg 46.06 & Fg 46.06 & Fg 13.05 & \\
\hline
\end{tabular}


Suitable plots were selected for next day inoculation in the afternoon before The necessary amount of inoculum was counted and prepared for the inoculation step next day and was kept until next morning in a cooler at $4^{\circ} \mathrm{C}$. The suspensions were stored on the field in cooled bags to avoid warming.

1) Spraying method combined with polyethylene bag coverage [1] [24] [25] [33]. The inoculation was performed with pure isolates, without any mixing. This way four epidemics were tested at the same time since the inocula exhibited different levels of aggressiveness. No environmental interaction was registered, as the different isolates were exposed to the same environment. In a single plot, the four isolates collected into two bunch of 15 - 20 heads apiece were sprayed from all sides to allow all spikelets to be covered. A group of heads was sprayed by $15-20 \mathrm{ml}$ suspension since the head sizes of the cultivars were different. In the hot year of 2000 it became clear that $24 \mathrm{hr}$. time periods were not nearly enough to cause severe disease. On one occasion we tested $18 \mathrm{hrs}$. of coverage, but the results were discouraging (unpublished), therefore no further test was made in this direction. 48 hrs. coverage since 2000 by polyethylene bags secured appropriate infection also under dry and warm conditions [see Figure 1(c) in Mesterházy et al. [6]. After removing the bags the sprayed heads remained loosely bound until harvest. Grausgruber et al. [54] tested 9 genotypes with the spraying and bag method compared with the cotton method. He received a fairly good correlation between the two methods, but FDK and DON were not tested.

2) Spraying method combined with mist irrigation. Inoculation was applied in the same manner; however following inoculation mist irrigation was used in the next two days after each inoculation event according to Buerstmayr et al. [12]. The labeling was the same as in Method 1.

3) Spawn method. The modified versions of the method are used, especially by breeders. This was the reason we included is test. Earlier we tested the spawn method using $F$. graminearum infected maize or other cereal grains [35] [51]. We had similar experience in several instances as de Villier [55]. Lemmens (pers. communication) in dry winter observed that no perithecia production was found; therefore the inoculum for inoculation in spite of misting was very sparse. Dill-Macky [35] was disappointed with the use of infected grains. However, Thomson [56] compared a spawn method with the spray and bag method and found significant, but not very high Spearman correlations between $r=0.41$ and 0.83 in 2008, and $r=0.22$ to 0.54 in 2009. Lemmens et al. [39] also came to a similar conclusion. Here more severe symptoms were achieved with the bagging method. This version did not have much success also in Szeged; therefore the maize stalk residue was used in this test (Figure 1). At the end of March corn debris was collected on another field and deposited into the experimental field, the rate about 20 - 30 stalk pieces of 15 - $30 \mathrm{~cm}$ length per square meter followed by application of misting 2 - 3 times a week after the stand had closed. In 2010 the perithecium production on the residue was good and wide spread (right picture of Figure 1), but a right inoculum density control was not made as no literature sources reported about it. In 2011 and 2012 the number of perithecia in spite of the watering was sparse, but visible infection

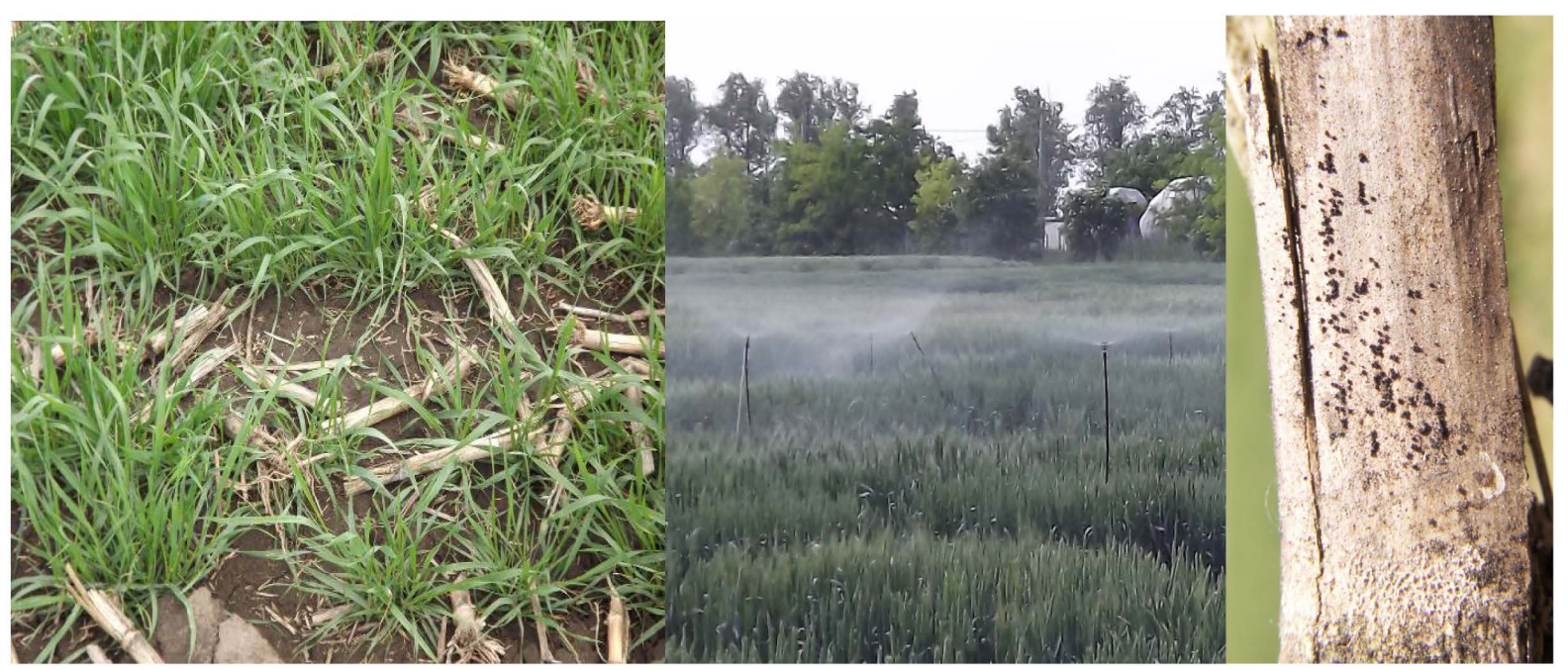

Figure 1. Maize stalk residue for the spawn method (left) and mist irrigation used in spawn method and spray + misting inoculation (middle) and perithecia on the residue (right). 
developed. 2015 was very interesting (not this test), where larger amount of residues were on the soil surface, perithecia in Mai were very sparsely, but following a week humid weather $90 \%$ of the heads had very severe infection. It seems that a direct and close correlation between perithecia number in infections severity is not always the case. At flowering the spawn test received twice about 30 - $30 \mathrm{~mm}$ was given to enhance infection for early and late genotypes, respectively. The two days misting protocol thereafter was also used here two weeks. About two weeks after flowering, two groups of heads were labeled the same way as that the sprayed heads were.

\subsection{Evaluation of Disease and Toxin Analysis}

The visual symptoms were rated according to Mesterházy [24] and Mesterházy et al. [6]. For spawn method the groups of heads were evaluated at dates like the other groups of heads in artificial inoculation to receive comparable data. The flowering dates corresponded as between the artificial an spawn method test was $3 \mathrm{~m}$ distance. The difference between flowering dates maximum one day difference was found. The data show the percentage of visually diseased spikelets, which correspond to the mean disease index. At harvest time the groups of heads were cut with a short stem that allows easier threshing [Seed Boy, Wintersteiger AG., Ried, Austria). All heads in the group were threshed. The air regulator was fully open to retain all small, infected or healthy, but shriveled grains. A fine cleaning was made using an EtsPlaut-Aubry air separator [41,290 Conan-Oucques, France). Wind speed was finely regulated to keep all infected and shriveled light grains. From the cleaned grains FDK was visually estimated as a percentage value $(0 \%-100 \%)$. Only the rose, white colored grains were considered together with the light infected whitish powdered grains. The normally colored, but shriveled grains were not included. This latter symptom is an indirect effect of the bleaching, meaning that the head part above the infection point of axis dies, and healthy, but shriveled grains are harvested.

For DON analysis the two samples of an isolate or the two groups of heads of spawn method from a given plot were pooled and mixed. Of this $6 \mathrm{~g}$ was separated, and milled with a Perten Laboratory mill (Laboratory Mill 3310, Perten Instruments, 12653 Hägersten, Sweden). The details of the DON analysis are given in Mesterházy et al. [25]. The only difference is that the measurements were made by an Agilent Infinity 1260 HPLC analyzer (Agilent Technologies Santa Clara, California, USA).

\subsection{Statistical Analysis}

The data of the two groups of heads for an isolate were averaged for FHB and FDK; they served as entries for the ANOVA analysis. Since for FHB a bunch was evaluated 4 - 5 times depending on the season, they represent the mean of 8 - 10 data. In FDK two data play the same role. For DON the grains of the two samples per isolates from a plot were pooled, so their DON content serves as entries. By this way 3840 data points were statistically evaluated for FHB, FDK and DON.

The stability of the behavior of genotypes was calculated according to Jalaluddin and Harrison [57], and Eberhart and Russel [58]. These methods were developed to measure yield stability during variety testing. We applied it for the first time to test disease resistance stability [Mesterházy [24]. The procedure is as follows: the columns represent the cultivars [40], while the rows contain the data for the individual epidemics [36] including years, epidemic severity, and methodical variants. So the data set is large enough to allow solid conclusions. The regression for each cultivar and trait will be counted between the mean of cultivars for 36 epidemic situations and the individual variety data. The "b" value of the linear regression is the stability index. When it is lower than one, it is positive, when higher, it mean very sharp responses under different conditions. The mean of all genotypes is one.

Correlation and regression analyses (Pearson) were performed using the built-in functions of Microsoft Excel. The four-way analyses were conducted via Microsoft Excel with the functions given by Sváb [59] and Weber [60]. When comparing the slopes for significance, the functions from Sváb [59] were used. In several cases, the statistical program SPSS (SPSS Hungary 1115 Budapest Bartók Béla street 105 - 113) was used.

The template is used to format your paper and style the text. All margins, column widths, line spaces, and text fonts are prescribed; please do not alter them. You may note peculiarities. For example, the head margin in this template measures proportionately more than is customary. This measurement and others are deliberate, using specifications that anticipate your paper as one part of the entire journals, and not as an independent document. Please do not revise any of the current designations. 


\section{Results}

\subsection{FHB Visual Data}

The FHB data reveal very large and highly significant variety differences (Table 2), such as FHB index values ranging from 3.62 to 16.74 (Incidence*severity). The spam and spray+bag method gave similar results [11.6\% and $10.2 \%)$; the spray + misting gave about $50 \%$ of these (6.78\%).

The correlations between the mean of the three methods had medium closeness (between $r=0.55$ and $r=0.73$, $\mathrm{p}=0.001$ ), meaning that with some difference show more or less similar ranking of the genotypes. The lowest correlation $(r=0.55, p=0.001)$ was calculated between spam and spray + bag; a somewhat closer correlation $(r$ $=0.66, p=0.001)$ between spray and bag and spray + misting and the closest correlation $(r=0.73, p=0.001)$ between the two mist irrigated inoculation methods. It seems that based on visual assessment none of the possible testing methods should be excluded. A large variation was observed between the three inoculation methods. The most resistant cultivars generally have low variance except ones such as Gallus or RSt/NB a. RSt/NB b, which react the opposite way, the lower data are at the spray + bag method, the other methods give higher indices. Among the medium susceptible genotypes GK Hattyu has a low variance with very similar performance under different inoculation methods. The susceptible GK Kalász presents the same very low variance indicating similarly high disease reactivity for the different methods. Therefore, a higher susceptibility does not mean a higher variance even the correlation between them is $r=0.56(p=0.001)$.

The influence of epidemic severity (Table 3 ) on the resistance expression shows significant differences is mean disease index. The mean of the lowest severity is $5.78 \%$ and the highest $15.97 \%$.

The correlations between the data of the three lower severities is similarly higher than $r=0.90, p=0.001$ (Table 3), only the very high severity data correlate less with the lower epidemic data, whereas the correlations between medium and high and high and very high are closer. For this reason the correlations and resistance expression data show an interaction with each other. The variance shows a rather high variability in disease reaction. The mean FHB performance correlates with the variance $r=0.39$ that shows only a loose correlation. In every resistance class we find very stable reactions, but the probability is higher in the more resistant genotypes.

The FHB variety reactions in the four year were very divergent [not shown in detail), in 2009 the mean disease index was $2.48 \%$, in 2010 it was $17.73 \%$, in 2011 it was $11.94 \%$, and 6\% in 2012. The very low values meant a disease index of less than $1 \%$. The correlation coefficients between the data of 2009 and other years were between $r=-0.15$ and 0.12 , which were not significant. This indicates that with very low disease index data without high differentiation no effective differentiation is possible, therefore a positive correlation with the data for other years is not in sight.

\subsection{FDK Evaluation}

The mean FDK values again show great variability, with a minimum value of 1.13 , and a maximum of $19.26 \%$, meaning a nearly 20 -fold difference (Table 4). The most severe infection was recorded in the spray + bag method with a value of $19.41 \%$. Here the differentiation was the most successful with values between $1.38 \%$ and $34.3 \%$, a 30 -fold difference. The LSD is low, with a value of only $1.41 \%$. The mean value of spray + misting method was only 5.72; the spawn method was only $4.62 \%$. It seems that for the FHB data the weight of the different methods diverges we found. The correlations show a medium $(r=0.55)$ closeness between the two inoculum spray methods $(\mathrm{p}=0.001)$, but the correlation was not significant between spraying + bag and spawn method $(r=0.27)$, but higher $(r=0.63, p=0.001)$ between the two mist application methods. The ranking of the cultivars is somewhat different, with the most resistant genotype being Nobeoka Bozu containing Ringo Star and two other lines combined with Zugoly on the third and fourth places. GK Fény, one of the most infected cultivars for FHB (but for FHB it was ranked as a moderately resistant cultivar), now ranks at the beginning of the table with $7.4 \%$, with a worst value of $19.26 \%$. The other two Nobeoka Bozu cultivar combinations rank in 3rd and 4th place. The variance varies between nearly zero to 215, with a mean of 81.9. It correlates with the average FDK performance of $r=0.43(p=0.01)$. The tendency is similarly apparent as with the disease index. The moderate correlation means that the more resistant genotypes tend to have significantly lower variance than susceptible ones, but a low variance genotype can be identified in all resistance classes. So the line RSt/NB b has a variance of 0.69 , with very low FDK values at all inoculation methods. GK Petur, a medium susceptible variety, is also stable with a variance of 27. GK Csillag has a similar resistance with an even a lower variance of 
Table 2. Comparison of FHB inoculation methods, visual rating, disease index \%, 2009-2012. The genotypes are ranked according to decreasing resistance according to the mean over all inoculation methods.

\begin{tabular}{|c|c|c|c|c|c|}
\hline \multirow{2}{*}{ Genotype } & \multicolumn{3}{|c|}{ Inoculation method } & \multirow{2}{*}{ Mean } & \multirow{2}{*}{ Variance } \\
\hline & Spray + Bag* & Spray $+M^{*}$ & Spam $+\mathrm{M}^{*}$ & & \\
\hline SzD $0016 \mathrm{~S}$ & 4.93 & 3.43 & 2.78 & 3.72 & 1.21 \\
\hline MIDAS & 4.99 & 1.49 & 4.87 & 3.78 & 3.95 \\
\hline SzD 5319 & 4.37 & 3.64 & 5.56 & 4.53 & 0.93 \\
\hline SzD 6401 & 7.24 & 3.93 & 3.07 & 4.75 & 4.84 \\
\hline SzD 4511 & 4.49 & 4.13 & 5.70 & 4.77 & 0.68 \\
\hline Zu//Ré/NB/5/DH Kö/In/4/Sgv/3/GT/Pdj2//Uhrt & 6.16 & 6.81 & 2.92 & 5.30 & 4.33 \\
\hline GALLUS (SzD 8583) & 9.29 & 3.15 & 3.50 & 5.31 & 11.92 \\
\hline SzD 5501 & 8.27 & 3.74 & 7.13 & 6.38 & 5.53 \\
\hline SzD $0016 \mathrm{~F}$ & 8.59 & 4.83 & 6.96 & 6.80 & 3.55 \\
\hline SzD 18364 (B-18364) & 7.80 & 5.52 & 7.31 & 6.88 & 1.44 \\
\hline Rst/NB a & 14.98 & 4.11 & 2.39 & 7.16 & 46.63 \\
\hline SzD 5066 & 8.81 & 5.49 & 7.27 & 7.19 & 2.76 \\
\hline GK SZALA & 12.45 & 3.62 & 6.84 & 7.64 & 19.97 \\
\hline SzD 5377 & 11.23 & 5.26 & 7.30 & 7.93 & 9.21 \\
\hline GK HUNYAD & 12.31 & 4.63 & 7.31 & 8.09 & 15.21 \\
\hline SzD 5275 & 8.77 & 7.30 & 8.27 & 8.12 & 0.56 \\
\hline GK PETUR & 8.84 & 7.92 & 7.99 & 8.25 & 0.26 \\
\hline Rst/NB b & 4.01 & 8.73 & 13.38 & 8.71 & 21.91 \\
\hline Ttj/RC103/3/Sgv/NB//MM/Sum3 & 11.10 & 4.70 & 10.52 & 8.78 & 12.52 \\
\hline GK HATTYU & 9.27 & 7.75 & 9.34 & 8.79 & 0.80 \\
\hline $\mathrm{Zu} / / \mathrm{Ré} / \mathrm{NB}$ b & 9.01 & 6.48 & 11.03 & 8.84 & 5.19 \\
\hline RAINER & 10.73 & 6.57 & 9.53 & 8.94 & 4.58 \\
\hline GK HOLLÓ & 8.57 & 6.67 & 12.67 & 9.31 & 9.40 \\
\hline SzD 6701 & 14.33 & 5.08 & 9.08 & 9.50 & 21.51 \\
\hline Zu//Ré/NB a & 9.20 & 7.18 & 13.62 & 10.00 & 10.84 \\
\hline SzD 7257 & 14.19 & 7.91 & 8.19 & 10.10 & 12.58 \\
\hline Be/SK 48.21//FHB 143 & 10.10 & 6.51 & 13.90 & 10.17 & 13.65 \\
\hline BALATON & 9.60 & 5.13 & 17.23 & 10.66 & 37.44 \\
\hline SzD 6515 & 13.47 & 8.90 & 9.61 & 10.66 & 6.04 \\
\hline SzD 6626 & 13.48 & 7.91 & 11.78 & 11.06 & 8.16 \\
\hline SzD 5205 & 17.40 & 7.14 & 9.21 & 11.25 & 29.44 \\
\hline Attila/3/Sgv/NB//MM/Sum2 & 15.34 & 7.83 & 13.47 & 12.22 & 15.30 \\
\hline GK KAPOS & 20.02 & 7.28 & 10.20 & 12.50 & 44.53 \\
\hline GK BÉKÉS & 18.15 & 7.94 & 15.31 & 13.80 & 27.78 \\
\hline GK FÉNY & 18.23 & 9.60 & 17.48 & 15.10 & 22.88 \\
\hline GK CSILLAG & 14.00 & 10.69 & 22.24 & 15.64 & 35.36 \\
\hline SzD 5417 & 23.67 & 12.99 & 11.00 & 15.89 & 46.38 \\
\hline
\end{tabular}


Continued

$\begin{array}{cccccc}\text { GK PIACOS } & 18.90 & 9.75 & 20.51 & 16.39 & 33.69 \\ \text { GK KALÁSZ } & 17.85 & 15.76 & 16.97 & 16.86 & 1.10 \\ \text { GK ÉLET } & 21.10 & 13.85 & 24.50 & 19.82 & 29.55 \\ \text { Mean } & 11.63 & 6.78 & 10.20 & 9.54 & 14.59 \\ \text { LSD 5\% genotypes } & & & 0.76 & \\ \text { LSD 5\% methods } & & & & 0.21 & \\ \text { Sp + Bag } & \text { Spawn + } M^{*} & \text { Spawn + M } & & \\ \text { Sp + M } & 0.67 & & & & \\ \text { Spam + M } & 0.55 & 0.73 & & & \\ \text { Mean } & 0.85 & 0.88 & 0.89 & & \\ \text { All significant at p }=0.001 & & & & \end{array}$

*Spray + bag, spray + misting, spawn + misting.

21 showing a very moderate variance to the general mean of 82. GK Kalász and GK Él et al. so show very low variance with a value of about 20, indicating a more uniform reaction until different inoculation is applied. On the other hand, SzD 5417 with its variance of 215 shows high susceptibility to the spray + bag method, but a reasonable good value for the spawn method. Therefore inoculation method may prefer or do not prefer given genotypes and may be a source of error in resistance tests.

The mean epidemic severity means were 3.33\%, 6.92\%, 10.47\% and 18.95\% (Table 5). The epidemic severity also influences genotype ranking. In spite of this, the correlations are close and significant. However, the lower epidemic severity shows a less close relation with the very high severity $(r=0.68)$ compared to the high or medium level epidemics ( $r=0.79,0.89, \mathrm{p}=0.001$, respectively). This is similar we found for FHB. Moreover, the correlations between the higher severity classes were closer, between 0.80 and 0.92 . We see that the variation for genotypes at low severity was between $0.78 \%$ and $7.68 \%$, for the highest severity they were between $1.85 \%$ and $31 \%$. The mean is 51, and the range is between 0.25 and 141 . The correlation between FDK mean and variance is nearly double, with a correlation of $r=0.77(p=0.001)$, which means a good agreement between resistance level and variance, e.g. the variance is lower for the more resistant genotypes than what we found for the more susceptible ones. The susceptible cultivars GK Kalász and GK Élet which have low variances as measured by the methods approximate to the average. SzD5417 also has a larger variance in this test, e.g. it reacts very differently under different disease pressures.

The year effect on the mean value of FDK is rather different. In 2009 it was 1.4\%, in 2010 it was $11.03 \%$, in 2011 it was $14.40 \%$ and in 2012 it was 12.83\%, the last three years being at the same level (data not shown in detail). The LSD $5 \%$ is $0.44 \%$ with the yearly values significantly differing from each other. The yearly data show a correlation of $r=0.56$ between 2009 and 2010 and $r=0.39$ between 2011 and 2012. The other correlations are between 0.15 and 0.17 , but are not significant. The variance mean is 65 , but the variation width is between 2.86 and 279.4. The more resistant cultivars have generally low values, in the first 20 cultivars only one surpassed the average of 65.4. In the second part 9 genotypes had values lower than the mean, and eight had a variance of over 100. Within this group two have very high levels of 240 and 279.

\subsection{DON Contamination}

The genotype differences are large and highly significant. The most resistant genotype has a value of $1.8 \mathrm{mg} / \mathrm{kg}$; the most contaminated had $13.9 \mathrm{mg} / \mathrm{kg}$ across 36 epidemic situations. The highest DON contamination was found for the spray + bag inoculation with a $14.47 \mathrm{mg} / \mathrm{kg}$ for the spray + misting gave 4.33 and only $2.11 \mathrm{mg} / \mathrm{kg}$ was found for the spawn method. The differences are highly significant. The data clearly show that the worst differentiation was found for the spawn method and the situation is somewhat better for the spray + mist method. It is remarkable that the best lines bread in Szeged performed very well in the test and produced the least DON among all genotypes tested. The correlations show the closest correlation between spray + bag and spray + misting methods; the other relations are less close. The variance of the three methods show a close correlation 
Table 3. Influence of epidemic severity on the FHB reactions, 2009-2012. The genotypes are ranked according to decreasing resistance according to the mean over all epidemic severities.

\begin{tabular}{|c|c|c|c|c|c|c|}
\hline \multirow[t]{2}{*}{ Genotype } & \multicolumn{4}{|c|}{ Mean } & \multirow{2}{*}{ Mean } & \multirow{2}{*}{ Variance } \\
\hline & Low & Medium & High & Very high & & \\
\hline SzD 0016 S & 1.15 & 1.50 & 3.10 & 9.12 & 3.72 & 13.70 \\
\hline MIDAS & 2.00 & 2.60 & 3.60 & 6.93 & 3.78 & 4.84 \\
\hline SzD 5319 & 2.25 & 2.80 & 4.39 & 8.65 & 4.53 & 8.38 \\
\hline SzD 6401 & 1.76 & 2.69 & 3.81 & 10.72 & 4.75 & 16.55 \\
\hline SzD 4511 & 2.42 & 2.89 & 4.43 & 9.36 & 4.77 & 10.07 \\
\hline $\begin{array}{c}\mathrm{Zu} / / \mathrm{Ré} / \mathrm{NB} / 5 / \mathrm{DH} \\
\mathrm{Kö/In/4/Sgv/3/GT/Pdj2//Uhrt}\end{array}$ & 4.86 & 4.50 & 4.76 & 7.06 & 5.30 & 1.41 \\
\hline GALLUS (SzD 8583) & 3.27 & 3.66 & 4.47 & 9.84 & 5.31 & 9.36 \\
\hline SzD 5501 & 3.63 & 3.63 & 5.28 & 12.98 & 6.38 & 19.96 \\
\hline SzD $0016 \mathrm{~F}$ & 4.41 & 5.51 & 6.25 & 11.01 & 6.80 & 8.47 \\
\hline SzD 18364 (B-18364) & 2.94 & 4.17 & 6.14 & 14.25 & 6.88 & 25.92 \\
\hline Rst/NB a & 3.20 & 5.40 & 6.68 & 13.37 & 7.16 & 19.20 \\
\hline SzD 5066 & 3.43 & 5.54 & 6.42 & 13.36 & 7.19 & 18.51 \\
\hline GK SZALA & 3.59 & 5.38 & 6.35 & 15.22 & 7.64 & 26.88 \\
\hline SzD 5377 & 3.34 & 4.95 & 7.68 & 15.76 & 7.93 & 30.46 \\
\hline GK HUNYAD & 4.24 & 6.19 & 7.03 & 14.89 & 8.09 & 21.91 \\
\hline SzD 5275 & 3.56 & 5.80 & 7.55 & 15.56 & 8.12 & 27.31 \\
\hline GK PETUR & 5.85 & 6.82 & 6.59 & 13.74 & 8.25 & 13.58 \\
\hline Rst/NB b & 7.19 & 8.16 & 8.11 & 11.36 & 8.71 & 3.33 \\
\hline Ttj/RC103/3/Sgv/NB//MM/Sum3 & 6.38 & 7.55 & 8.10 & 13.08 & 8.78 & 8.75 \\
\hline GK HATTYU & 5.84 & 8.20 & 7.70 & 13.41 & 8.79 & 10.53 \\
\hline $\mathrm{Zu} / / \mathrm{Ré} / \mathrm{NB}$ b & 6.92 & 8.15 & 8.12 & 12.16 & 8.84 & 5.22 \\
\hline RAINER & 4.88 & 6.62 & 7.86 & 16.42 & 8.94 & 26.30 \\
\hline GK HOLLÓ & 6.63 & 8.58 & 9.08 & 12.93 & 9.31 & 6.97 \\
\hline SzD 6701 & 3.87 & 5.92 & 7.77 & 20.42 & 9.50 & 55.57 \\
\hline $\mathrm{Zu} / / \mathrm{Ré} / \mathrm{NB}$ a & 8.48 & 9.59 & 8.92 & 13.00 & 10.00 & 4.22 \\
\hline SzD 7257 & 3.55 & 6.81 & 9.01 & 21.01 & 10.10 & 57.97 \\
\hline Be/SK 48.21//FHB 143 & 6.85 & 8.34 & 9.33 & 16.17 & 10.17 & 17.04 \\
\hline BALATON & 7.82 & 9.68 & 10.09 & 15.02 & 10.66 & 9.45 \\
\hline SzD 6515 & 4.48 & 6.58 & 10.07 & 21.51 & 10.66 & 57.66 \\
\hline SzD 6626 & 5.25 & 7.39 & 9.53 & 22.06 & 11.06 & 56.84 \\
\hline SzD 5205 & 5.18 & 8.10 & 10.02 & 21.71 & 11.25 & 52.52 \\
\hline Attila/3/Sgv/NB//MM/Sum2 & 8.66 & 11.98 & 12.14 & 16.08 & 12.22 & 9.21 \\
\hline GK KAPOS & 5.61 & 8.53 & 11.33 & 24.54 & 12.50 & 69.82 \\
\hline
\end{tabular}


Continued

\begin{tabular}{|c|c|c|c|c|c|c|}
\hline GK BÉKÉS & 8.91 & 12.29 & 13.01 & 21.00 & 13.80 & 26.19 \\
\hline GK FÉNY & 11.57 & 13.88 & 14.78 & 20.18 & 15.10 & 13.29 \\
\hline GK CSILLAG & 12.06 & 15.41 & 15.31 & 19.79 & 15.64 & 10.06 \\
\hline SzD 5417 & 7.38 & 10.52 & 14.73 & 30.92 & 15.89 & 109.57 \\
\hline GK PIACOS & 12.16 & 15.78 & 14.62 & 22.99 & 16.39 & 21.67 \\
\hline GK KALÁSZ & 11.76 & 15.71 & 16.36 & 23.59 & 16.86 & 24.28 \\
\hline GK ÉLET & 13.94 & 18.55 & 19.07 & 27.70 & 19.82 & 32.91 \\
\hline Mean & 5.78 & 7.66 & 8.74 & 15.97 & 9.54 & 13.70 \\
\hline LSD 5\% & & & & & 3.72 & 4.84 \\
\hline Correlations & Low & Medium & High & Very high & & \\
\hline Medium & 0.98 & & & & & \\
\hline High & 0.91 & 0.96 & & & & \\
\hline Very high & 0.58 & 0.70 & 0.84 & & & \\
\hline Mean & 0.90 & 0.96 & 0.996 & 0.87 & & \\
\hline
\end{tabular}

All are significant at $\mathrm{p}=0.001$.

with the means for genotypes $(r=0.81, p=0.001)$, indicating that the most resistant genotypes have less DON and also lower variance values. It is remarkable that the variance correlated best with the DON data of the spray + bag method, medium with the spray + misting inoculation and significant relation was found with the spawn method. However, among highly susceptible cultivars a low variance may also occur such as with GK Kalász where the reaction to different methods shows relative high values (Table 6).

The epidemic levels differed greatly, with the general mean values of $2.41,4.43 .7 .04$ and $13.99 \mathrm{mg} / \mathrm{kg}$ (Table 7). All correlation coefficients are significant at $\mathrm{p}=0.001$. The values were less close between low and very high epidemic severities than between low and medium, medium and high and high and very high classes. The variance correlated well with mean performance $(r=0.76, p=0.001)$, but there are exceptions such as GK Kalász or GK Holló where the variance is low, but DON contamination is high in all epidemic situations. We must add that at high epidemic severities the correlations between variance and mean performance are significantly closer. However, there are highly susceptible genotypes with lower variance (GK Kalász, GK Piacos) that have relative high values at all epidemic severities. It seems that different epidemic severities across years provide useful differentiation also at lower epidemic level.

The year influenced the DON contamination significantly (Table 8). For the FHB visual data and FDK we did not provide detailed data in this respect, but we do so here, because only limited information is present for DON and its significance is large. In 2009 the mean was $0.98 \mathrm{mg} / \mathrm{kg}$, in $20106.30 \mathrm{mg} / \mathrm{kg}$, in $201115.12 \mathrm{mg} / \mathrm{kg}$ and in $20124.30 \mathrm{mg} / \mathrm{kg}$ were measured. The correlations were all significant, but they varied between $\mathrm{r}=0.34$ and $r=0.78$., much larger that the epidemic severity data did. Looking at the correlations between the values for individual years and mean, 2011 gave the closest relation since this year produced the highest toxin concentration. Of the three traits we received the highest correlations with DON.

\subsection{Comparison of Inoculation Methods}

The comparison of the three inoculation methods (Table 9) shows the mean data for the three traits and methods that among inoculation methods the spray + bag method showed the best differentiation for all traits. Of the four years except 2009 all gave the best differentiation of the genotypes. The two other methods normally gave much lower values. The spray + misting method gave acceptable differentiation for only two years, but a much lower level than the spray + bag method did. The least effective was the spawn method, where some differentiation was found during one of the four years. The different response of the traits is also clear. In 2010 the spawn method surprisingly showed severe infection. However, the FDK correlated well with the 2011 value and the DON 
Table 4. Comparison of FHB inoculation methods, FDK\%, 2009-2012. The genotypes are ranked according to decreasing resistance according to the mean over all inoculation methods.

\begin{tabular}{|c|c|c|c|c|c|}
\hline \multirow{2}{*}{ Genotype } & \multicolumn{3}{|c|}{ Inoculation method } & \multirow{2}{*}{ Mean } & \multirow{2}{*}{ Variance } \\
\hline & Spray + Bag* & Spray + M & Spam + M & & \\
\hline Rst/NB b & 1.38 & 0.21 & 1.81 & 1.13 & 0.69 \\
\hline GALLUS (SzD 8583) & 10.98 & 0.89 & 0.19 & 4.02 & 36.43 \\
\hline $\mathrm{Zu} / / \mathrm{Ré} / \mathrm{NB}$ a & 9.85 & 2.81 & 0.75 & 4.47 & 22.79 \\
\hline $\mathrm{Zu} / / \mathrm{Ré} / \mathrm{NB} \mathrm{b}$ & 14.15 & 1.79 & 1.31 & 5.75 & 52.98 \\
\hline SzD 5319 & 12.85 & 3.93 & 1.41 & 6.06 & 36.09 \\
\hline Zu//Ré/NB/5/DH Kö/In/4/Sgv/3/GT/Pdj2//Uhrt & 15.94 & 1.57 & 0.81 & 6.11 & 72.66 \\
\hline MIDAS & 14.29 & 1.79 & 2.39 & 6.16 & 49.70 \\
\hline SzD $0016 \mathrm{~F}$ & 14.34 & 2.74 & 1.63 & 6.23 & 49.53 \\
\hline SzD 0016 S & 13.88 & 4.44 & 1.00 & 6.44 & 44.45 \\
\hline Ttj/RC103/3/Sgv/NB//MM/Sum3 & 17.07 & 3.05 & 1.54 & 7.22 & 73.40 \\
\hline Rst/NB a & 11.83 & 6.37 & 3.75 & 7.32 & 17.00 \\
\hline GK FÉNY & 18.94 & 2.66 & 0.56 & 7.39 & 101.16 \\
\hline SzD 5066 & 18.06 & 4.04 & 0.73 & 7.61 & 84.66 \\
\hline SzD 5501 & 16.92 & 4.11 & 3.19 & 8.07 & 58.84 \\
\hline SzD 18364 (B-18364) & 13.78 & 7.33 & 4.89 & 8.67 & 21.09 \\
\hline Attila/3/Sgv/NB//MM/Sum3 & 19.08 & 4.00 & 3.56 & 8.88 & 78.05 \\
\hline SzD 6401 & 20.11 & 3.36 & 3.25 & 8.91 & 94.13 \\
\hline SzD 5205 & 20.33 & 5.07 & 2.00 & 9.13 & 96.37 \\
\hline SzD 4511 & 19.64 & 6.66 & 1.16 & 9.15 & 90.09 \\
\hline GK BÉKÉS & 15.07 & 5.31 & 7.56 & 9.32 & 26.13 \\
\hline SzD 6701 & 20.85 & 4.05 & 4.16 & 9.69 & 93.45 \\
\hline Be/SK 48.21//FHB 143 & 23.15 & 4.48 & 1.51 & 9.71 & 137.68 \\
\hline SzD 6626 & 20.48 & 4.48 & 4.69 & 9.88 & 84.18 \\
\hline GK HOLLÓ & 13.55 & 4.84 & 11.44 & 9.94 & 81.00 \\
\hline GK CSILLAG & 20.33 & 4.86 & 4.63 & 9.94 & 20.64 \\
\hline GK PETUR & 16.32 & 6.08 & 9.44 & 10.61 & 27.21 \\
\hline GK HUNYAD & 25.89 & 3.64 & 3.25 & 10.93 & 168.00 \\
\hline RAINER & 25.24 & 4.99 & 3.13 & 11.12 & 150.40 \\
\hline SzD 5377 & 25.88 & 7.33 & 1.38 & 11.53 & 163.37 \\
\hline GK SZALA & 27.63 & 5.16 & 3.39 & 12.06 & 182.64 \\
\hline SzD 7257 & 27.54 & 9.08 & 1.19 & 12.60 & 182.91 \\
\hline BALATON & 25.51 & 5.15 & 7.44 & 12.70 & 124.31 \\
\hline GK HATTYU & 25.03 & 5.03 & 12.38 & 14.14 & 102.38 \\
\hline SzD 5417 & 31.26 & 9.02 & 3.50 & 14.59 & 215.92 \\
\hline GK KAPOS & 27.77 & 10.25 & 6.69 & 14.90 & 127.38 \\
\hline GK KALÁSZ & 20.09 & 10.86 & 14.56 & 15.17 & 21.55 \\
\hline SzD 5275 & 24.49 & 17.59 & 6.73 & 16.27 & 80.23 \\
\hline GK PIACOS & 21.09 & 11.86 & 17.00 & 16.65 & 21.36 \\
\hline GK ÉLET & 21.67 & 15.45 & 13.76 & 16.96 & 17.35 \\
\hline SzD 6515 & 34.28 & 12.58 & 10.94 & 19.26 & 169.73 \\
\hline Mean & 19.41 & 5.72 & 4.62 & 9.92 & 81,9 \\
\hline \multirow[t]{2}{*}{ LSD 5\% } & & & & 1.41 & \\
\hline & Spray + Bag* & Spray + M & Spam + M & & \\
\hline Spray + M & $0.56^{* * *}$ & & & & \\
\hline Spam + M & 0.28 & $0.63^{* * *}$ & & & \\
\hline Mean & $0.83^{* * *}$ & $0.86^{* * *}$ & $0.72^{* * *}$ & & \\
\hline
\end{tabular}

\footnotetext{
${ }^{* * *} \mathrm{p}=0.001$.
} 
Table 5. Comparison of FHB inoculation methods, FDK, epidemic severity \%, 2009-2012. The genotypes are ranked according to decreasing resistance according to the mean over all epidemic severities.

\begin{tabular}{|c|c|c|c|c|c|c|}
\hline \multirow{2}{*}{ Genotype } & \multicolumn{4}{|c|}{ Epidemic severity } & \multirow{2}{*}{ Mean } & \multirow{2}{*}{ Variance } \\
\hline & Low & Medium & High & Very high & & \\
\hline Rst/NB b & 0.78 & 0.79 & 1.11 & 1.85 & 1.13 & 0.25 \\
\hline GALLUS (SzD 8583) & 0.49 & 2.53 & 4.50 & 8.56 & 4.02 & 11.85 \\
\hline Zu//Ré/NB a & 2.44 & 3.13 & 4.40 & 7.92 & 4.47 & 5.95 \\
\hline $\mathrm{Zu} / /$ Ré/NB b & 1.22 & 4.28 & 6.68 & 10.83 & 5.75 & 16.44 \\
\hline SzD 5319 & 0.96 & 2.51 & 6.85 & 13.93 & 6.06 & 33.68 \\
\hline Zu//Ré/NB/5/DH Kö/In/4/Sgv/3/GT/Pdj2//Uhrt & 1.61 & 4.18 & 8.20 & 10.43 & 6.11 & 15.65 \\
\hline MIDAS & 1.95 & 3.73 & 6.62 & 12.32 & 6.16 & 20.57 \\
\hline SzD $0016 \mathrm{~F}$ & 0.99 & 2.76 & 5.80 & 15.39 & 6.23 & 41.22 \\
\hline SzD $0016 \mathrm{~S}$ & 1.07 & 2.71 & 6.37 & 15.61 & 6.44 & 42.25 \\
\hline Ttj/RC103/3/Sgv/NB//MM/Sum3 & 1.84 & 4.67 & 7.67 & 14.70 & 7.22 & 30.52 \\
\hline Rst/NB a & 2.38 & 5.25 & 5.84 & 15.80 & 7.32 & 34.23 \\
\hline GK FÉNY & 1.67 & 4.74 & 7.57 & 15.57 & 7.39 & 35.54 \\
\hline SzD 5066 & 0.71 & 3.88 & 8.70 & 17.14 & 7.61 & 51.17 \\
\hline SzD 5501 & 2.49 & 3.77 & 8.76 & 17.27 & 8.07 & 44.91 \\
\hline SzD 18364 (B-18364) & 2.43 & 5.05 & 8.41 & 18.76 & 8.67 & 51.30 \\
\hline Attila/3/Sgv/NB//MM/Sum3 & 4.19 & 7.93 & 9.40 & 14.01 & 8.88 & 16.50 \\
\hline SzD 6401 & 2.14 & 6.33 & 10.36 & 16.80 & 8.91 & 38.95 \\
\hline SzD 5205 & 1.42 & 5.91 & 8.69 & 20.52 & 9.13 & 66.55 \\
\hline SzD 4511 & 2.20 & 5.56 & 9.41 & 19.44 & 9.15 & 55.72 \\
\hline GK BÉKÉS & 4.90 & 6.41 & 10.03 & 15.92 & 9.32 & 24.04 \\
\hline SzD 6701 & 2.37 & 5.88 & 11.31 & 19.20 & 9.69 & 53.77 \\
\hline Be/SK 48.21//FHB 142 & 3.62 & 8.03 & 8.92 & 18.29 & 9.71 & 38.06 \\
\hline SzD 6626 & 2.99 & 7.67 & 8.28 & 20.59 & 9.88 & 56.54 \\
\hline GK CSILLAG & 3.61 & 9.51 & 12.55 & 14.08 & 9.94 & 21.41 \\
\hline GK HOLLÓ & 4.97 & 6.92 & 10.55 & 17.33 & 9.94 & 29.61 \\
\hline GK PETUR & 4.92 & 7.04 & 10.25 & 20.23 & 10.61 & 45.91 \\
\hline GK HUNYAD & 3.59 & 7.86 & 10.94 & 21.31 & 10.93 & 56.99 \\
\hline RAINER & 4.62 & 6.81 & 8.50 & 24.53 & 11.12 & 82.53 \\
\hline SzD 5377 & 3.06 & 5.91 & 13.24 & 23.91 & 11.53 & 86.54 \\
\hline GK SZALA & 3.24 & 8.90 & 13.36 & 22.74 & 12.06 & 67.81 \\
\hline SzD 7257 & 1.95 & 7.48 & 14.34 & 26.65 & 12.60 & 113.29 \\
\hline BALATON & 3.74 & 9.66 & 14.33 & 23.06 & 12.70 & 66.51 \\
\hline GK HATTYU & 6.63 & 10.19 & 15.18 & 24.58 & 14.14 & 60.65 \\
\hline SzD 5417 & 4.17 & 9.12 & 13.63 & 31.46 & 14.59 & 141.33 \\
\hline GK KAPOS & 5.04 & 11.43 & 14.43 & 28.72 & 14.90 & 100.16 \\
\hline GK KALÁSZ & 8.48 & 12.35 & 15.03 & 24.82 & 15.17 & 48.59 \\
\hline SzD 5275 & 6.10 & 11.31 & 18.85 & 28.81 & 16.27 & 97.32 \\
\hline GK PIACOS & 7.48 & 14.09 & 18.31 & 26.72 & 16.65 & 64.92 \\
\hline GK ÉLET & 7.68 & 14.82 & 18.59 & 26.74 & 16.96 & 63.00 \\
\hline SzD 6515 & 7.01 & 15.67 & 22.85 & 31.52 & 19.26 & 108.70 \\
\hline Mean & 3.33 & 6.92 & 10.47 & 18.95 & 9.92 & 51.02 \\
\hline LSD 5\% & & & & & 1.41 & \\
\hline Correlations & Low & Medium & High & Very high & & \\
\hline Medium & 0.89 & & & & & \\
\hline High & 0.80 & 0.93 & & & & \\
\hline Very high & 0.68 & 0.81 & 0.86 & & & \\
\hline Mean & 0.85 & 0.95 & 0.97 & 0.94 & & \\
\hline All significant at $\mathrm{p}=0.001$ & & & & & & \\
\hline
\end{tabular}


Table 6. Influence of inoculation methods on the DON contamination in wheat methodical study, 2009-2012. The genotypes are ranked according to decreasing resistance according to the mean over all inoculation methods.

\begin{tabular}{|c|c|c|c|c|c|}
\hline \multirow{2}{*}{ Genotype } & \multicolumn{3}{|c|}{ Inoculation method } & \multirow{2}{*}{ Mean } & \multirow{2}{*}{ Variance } \\
\hline & Spray + bag & Spray + M & Spawn & & \\
\hline Rst/NB b & 3.16 & 0.65 & 1.60 & 1.80 & 1.61 \\
\hline $\mathrm{Zu} / / \mathrm{Ré} / \mathrm{Nb}$ a & 4.45 & 0.74 & 1.15 & 2.12 & 4.14 \\
\hline Zu//Ré/NB b & 6.57 & 1.74 & 0.95 & 3.09 & 9.24 \\
\hline Zu//Ré/NB/5/DH Kö/In/4/Sgv/3/GT/Pdj2//Uhrt & 7.22 & 1.62 & 1.27 & 3.37 & 11.17 \\
\hline SzD 5319 & 7.62 & 2.20 & 0.76 & 3.53 & 13.09 \\
\hline MIDAS & 8.90 & 2.62 & 1.26 & 4.26 & 16.58 \\
\hline SzD 4511 & 9.39 & 3.34 & 0.79 & 4.50 & 19.50 \\
\hline GALLUS (SzD 8583) & 10.52 & 1.67 & 1.46 & 4.55 & 26.73 \\
\hline SzD 5066 & 11.00 & 2.33 & 0.81 & 4.72 & 30.24 \\
\hline SzD 0016 S & 10.16 & 3.39 & 0.70 & 4.75 & 23.73 \\
\hline BALATON & 10.78 & 2.44 & 1.16 & 4.79 & 27.31 \\
\hline Ttj/RC103/3/Sgv/NB//MM/Sum3 & 10.64 & 3.04 & 1.67 & 5.11 & 23.36 \\
\hline SzD $0016 \mathrm{~F}$ & 11.01 & 3.16 & 1.41 & 5.19 & 26.12 \\
\hline SzD 5501 & 9.69 & 4.62 & 1.33 & 5.21 & 17.74 \\
\hline SzD 6401 & 12.51 & 3.70 & 1.07 & 5.76 & 35.92 \\
\hline GK FÉNY & 13.85 & 2.44 & 1.02 & 5.77 & 49.47 \\
\hline GK HOLLÓ & 10.92 & 3.71 & 2.79 & 5.81 & 19.84 \\
\hline GK CSILLAG & 13.56 & 2.44 & 2.82 & 6.27 & 39.85 \\
\hline RAINER & 15.51 & 2.93 & 1.12 & 6.52 & 61.39 \\
\hline GK BÉKÉS & 13.33 & 4.04 & 2.25 & 6.54 & 35.39 \\
\hline Attila/3/Sgv/NB//MM/Sum3 & 12.58 & 3.87 & 3.40 & 6.62 & 26.71 \\
\hline GK HATTYU & 13.24 & 3.96 & 3.44 & 6.88 & 30.41 \\
\hline SzD 6626 & 15.82 & 5.04 & 0.89 & 7.25 & 59.39 \\
\hline GK PETUR & 11.98 & 4.80 & 5.15 & 7.31 & 16.40 \\
\hline Be/SK 48.21//FHB 143 & 13.47 & 6.25 & 2.52 & 7.41 & 31.00 \\
\hline $\mathrm{Rst} / \mathrm{Nb}$ a & 14.98 & 5.88 & 1.90 & 7.59 & 44.99 \\
\hline SzD 5377 & 16.01 & 6.31 & 1.13 & 7.82 & 57.09 \\
\hline GK HUNYAD & 21.14 & 3.04 & 1.16 & 8.44 & 121.72 \\
\hline SzD 18364 (B-18364) & 18.45 & 6.08 & 1.46 & 8.66 & 77.15 \\
\hline GK ÉLET & 18.66 & 5.53 & 3.18 & 9.13 & 69.59 \\
\hline SzD 5205 & 21.68 & 4.69 & 1.59 & 9.32 & 116.96 \\
\hline GK SZALA & 20.78 & 6.05 & 2.21 & 9.68 & 96.08 \\
\hline SzD 6701 & 21.57 & 5.64 & 1.96 & 9.72 & 108.70 \\
\hline SzD 5417 & 23.64 & 3.18 & 3.16 & 9.99 & 139.64 \\
\hline SzD 5275 & 15.61 & 11.57 & 4.12 & 10.43 & 34.01 \\
\hline SzD 6515 & 23.28 & 6.09 & 2.49 & 10.62 & 123.46 \\
\hline GK PIACOS & 20.69 & 7.66 & 5.28 & 11.21 & 68.83 \\
\hline GK KALÁSZ & 18.44 & 8.94 & 7.07 & 11.48 & 37.19 \\
\hline SzD 7257 & 25.79 & 7.13 & 2.07 & 11.66 & 155.99 \\
\hline GK KAPOS & 30.04 & 8.66 & 2.91 & 13.87 & 204.43 \\
\hline Mean & 14.47 & 4.33 & 2.11 & 6.97 & 52.80 \\
\hline LSD 5\% between genotypes & & & & 2.14 & \\
\hline LSD 5\% between methods & & & & 0.59 & \\
\hline Correlations & Spray + bag & Spray + M & & $+M$ & Mean \\
\hline Spray + M & $0.67^{* * *}$ & & & & \\
\hline Spawn & $0.36^{*}$ & $0.60^{* * *}$ & & & \\
\hline Mean & $0.95^{* * *}$ & $0.85^{* * *}$ & & & \\
\hline Variance & $0.94^{* * *}$ & 0.47 & & & $0.81^{* * *}$ \\
\hline
\end{tabular}

${ }^{* * *} \mathrm{p}=0.001, \stackrel{*}{\mathrm{p}}=0.05$. 
Table 7. Influence of the epidemic severity on the DON expression in the methodical trial 2009-2012. The genotypes are ranked according to decreasing resistance according to the mean over all epidemic severities.

\begin{tabular}{|c|c|c|c|c|c|c|}
\hline \multirow{2}{*}{ Genotype } & \multicolumn{4}{|c|}{ Epidemic level } & \multirow{2}{*}{ Mean } & \multirow{2}{*}{ Variance } \\
\hline & Low & Medium & High & Very high & & \\
\hline Rst/NB b & 0.94 & 1.49 & 1.74 & 3.04 & 1.80 & 0.79 \\
\hline $\mathrm{Zu} / / \mathrm{Ré} / \mathrm{NB}$ a & 0.81 & 1.03 & 2.69 & 3.94 & 2.12 & 2.18 \\
\hline Zu//Ré/NB b & 1.45 & 1.45 & 2.94 & 6.51 & 3.09 & 5.70 \\
\hline Zu//Ré/NB/5/DH Kö/In/4/Sgv/3/GT/Pdj2//Uhrt & 1.51 & 2.55 & 3.15 & 6.27 & 3.37 & 4.20 \\
\hline SzD 5319 & 1.03 & 1.42 & 4.01 & 7.65 & 3.53 & 9.31 \\
\hline MIDAS & 1.22 & 2.65 & 3.88 & 9.29 & 4.26 & 12.44 \\
\hline SzD 4511 & 1.21 & 2.51 & 5.19 & 9.11 & 4.50 & 12.16 \\
\hline GALLUS (SzD 8583) & 1.19 & 2.91 & 4.67 & 9.43 & 4.55 & 12.59 \\
\hline SzD 5066 & 1.15 & 1.96 & 4.02 & 11.74 & 4.72 & 23.39 \\
\hline SzD $0016 \mathrm{~S}$ & 1.42 & 2.10 & 4.90 & 10.58 & 4.75 & 17.34 \\
\hline BALATON & 1.11 & 2.37 & 3.76 & 11.93 & 4.79 & 23.84 \\
\hline Ttj/RC103/3/Sgv/NB//MM/Sum3 & 1.92 & 3.81 & 3.73 & 10.99 & 5.11 & 16.11 \\
\hline SzD $0016 \mathrm{~F}$ & 1.31 & 2.13 & 5.81 & 11.53 & 5.19 & 21.67 \\
\hline SzD 5501 & 2.17 & 3.22 & 5.08 & 10.38 & 5.21 & 13.30 \\
\hline SzD 6401 & 1.65 & 3.27 & 5.78 & 12.35 & 5.76 & 22.17 \\
\hline GK FÉNY & 1.97 & 2.81 & 5.05 & 13.26 & 5.77 & 26.59 \\
\hline GK HOLLÓ & 2.24 & 5.72 & 6.23 & 9.04 & 5.81 & 7.80 \\
\hline GK CSILLAG & 2.64 & 3.93 & 8.27 & 10.24 & 6.27 & 12.80 \\
\hline RAINER & 2.78 & 2.53 & 5.38 & 15.38 & 6.52 & 36.59 \\
\hline GK BÉKÉS & 3.68 & 4.87 & 7.35 & 10.25 & 6.54 & 8.45 \\
\hline Attila/3/Sgv/NB//MM/Sum3 & 2.55 & 4.58 & 7.44 & 11.90 & 6.62 & 16.40 \\
\hline GK HATTYU & 2.88 & 5.45 & 5.77 & 13.42 & 6.88 & 20.69 \\
\hline SzD 6626 & 1.97 & 3.01 & 5.67 & 18.37 & 7.25 & 57.33 \\
\hline GK PETUR & 3.40 & 4.34 & 6.34 & 15.15 & 7.31 & 28.85 \\
\hline Be/SK 48.21//FHB 143 & 2.65 & 4.98 & 5.91 & 16.10 & 7.41 & 35.47 \\
\hline Rst/NB a & 1.94 & 4.65 & 6.11 & 17.66 & 7.59 & 48.06 \\
\hline SzD 5377 & 2.43 & 4.05 & 9.09 & 15.70 & 7.82 & 35.63 \\
\hline GK HUNYAD & 2.19 & 10.10 & 8.41 & 13.06 & 8.44 & 21.05 \\
\hline SzD 18364 (B-18364) & 2.97 & 4.94 & 11.16 & 15.56 & 8.66 & 33.37 \\
\hline GK ÉLET & 4.91 & 8.54 & 9.90 & 13.15 & 9.13 & 11.64 \\
\hline SzD 5205 & 2.10 & 3.24 & 10.55 & 21.39 & 9.32 & 78.76 \\
\hline GK SZALA & 2.67 & 6.39 & 10.17 & 19.48 & 9.68 & 52.03 \\
\hline SzD 6701 & 2.70 & 5.51 & 9.87 & 20.81 & 9.72 & 63.34 \\
\hline SzD 5417 & 2.42 & 5.93 & 12.26 & 19.36 & 9.99 & 55.57 \\
\hline SzD 5275 & 5.36 & 5.92 & 10.62 & 19.84 & 10.43 & 44.87 \\
\hline SzD 6515 & 3.09 & 5.76 & 10.47 & 23.16 & 10.62 & 79.21 \\
\hline GK PIACOS & 5.28 & 8.25 & 13.79 & 17.53 & 11.21 & 30.17 \\
\hline GK KALÁSZ & 5.62 & 11.23 & 11.21 & 17.89 & 11.48 & 25.21 \\
\hline SzD 7257 & 2.57 & 6.25 & 9.02 & 28.82 & 11.66 & 137.73 \\
\hline GK KAPOS & 3.32 & 9.43 & 14.42 & 28.30 & 13.87 & 113.22 \\
\hline Mean & 2.41 & 4.43 & 7.04 & 13.99 & 6.97 & 31.95 \\
\hline LSD 5\% genotypes & & & & & 2.14 & \\
\hline LSD 5\% between epidemic severities & & & & & 0.68 & \\
\hline
\end{tabular}

\begin{tabular}{|c|c|c|c|c|c|}
\hline & Low & Medium & High & Very high & Mean \\
\hline Medium & $0.78^{* * *}$ & & & & \\
\hline High & $0.74^{* * *}$ & $0.7871^{* * *}$ & & & \\
\hline Very high & $0.51^{* * *}$ & $0.59^{* * *}$ & $0.78^{* * *}$ & & \\
\hline Mean & $0.75^{* * *}$ & $0.83^{* * *}$ & $0.94^{* * *}$ & $0.92^{* * *}$ & \\
\hline Variance & 0.25 & $0.38^{*}$ & $0.60^{* * *}$ & $0.93^{* * *}$ & $0.76^{* * *}$ \\
\hline
\end{tabular}

${ }^{* * *} \mathrm{p}=0.001,{ }^{*} \mathrm{p}=0.05$ 
Table 8. Influence of years on the DON contamination expression in the methodological trial, 2009-2012. The genotypes are ranked according to decreasing resistance according to the mean over all years.

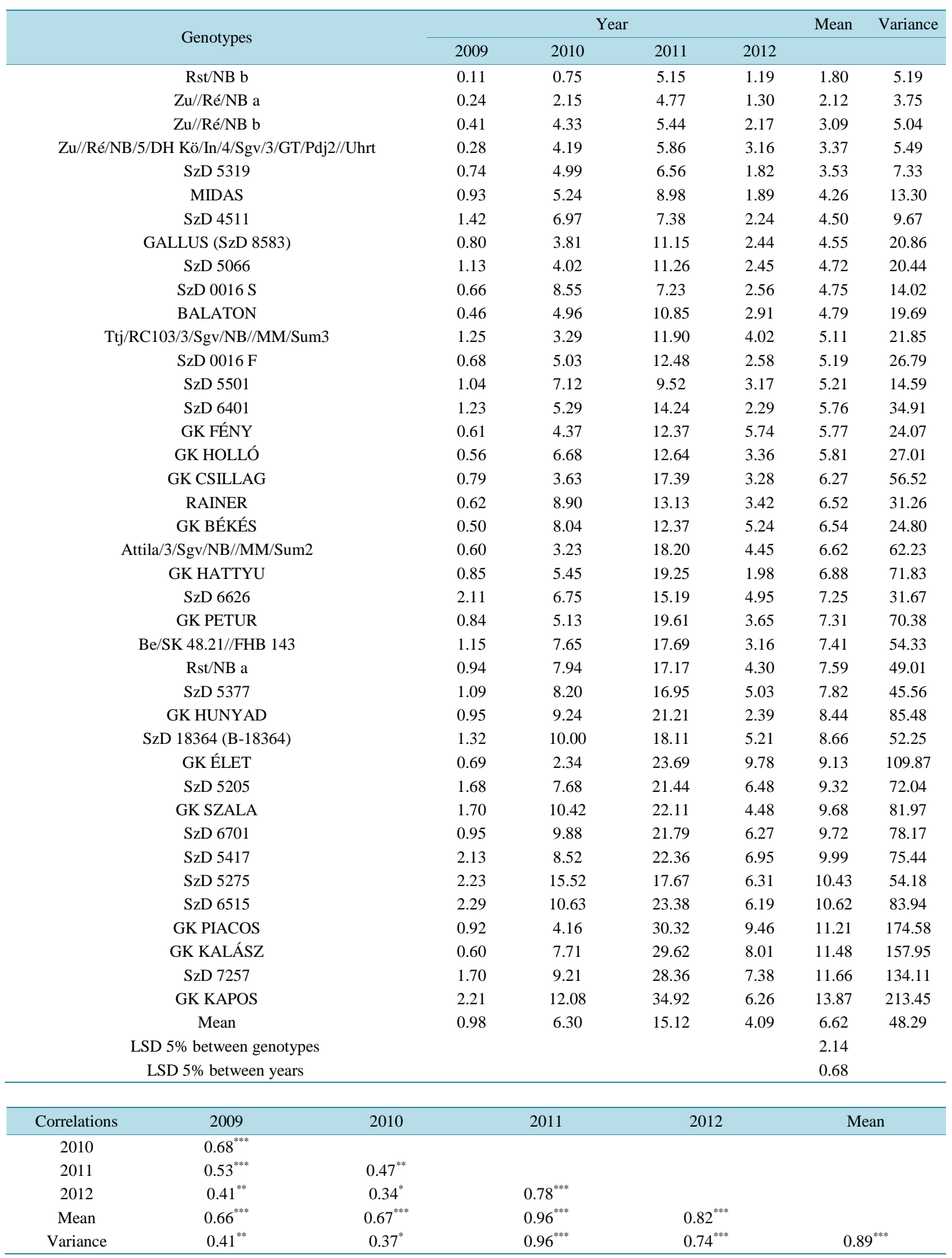

${ }^{* * *} \mathrm{p}=0.001, \stackrel{* *}{\mathrm{p}}=0.01, \stackrel{*}{\mathrm{p}}=0.05$ 
Table 9. Comparison of the inoculation methods for FHB, FDK and DON resistance, 2009-2012. Data are across epidemic situations and cultivars in the units they were estimated or measured.

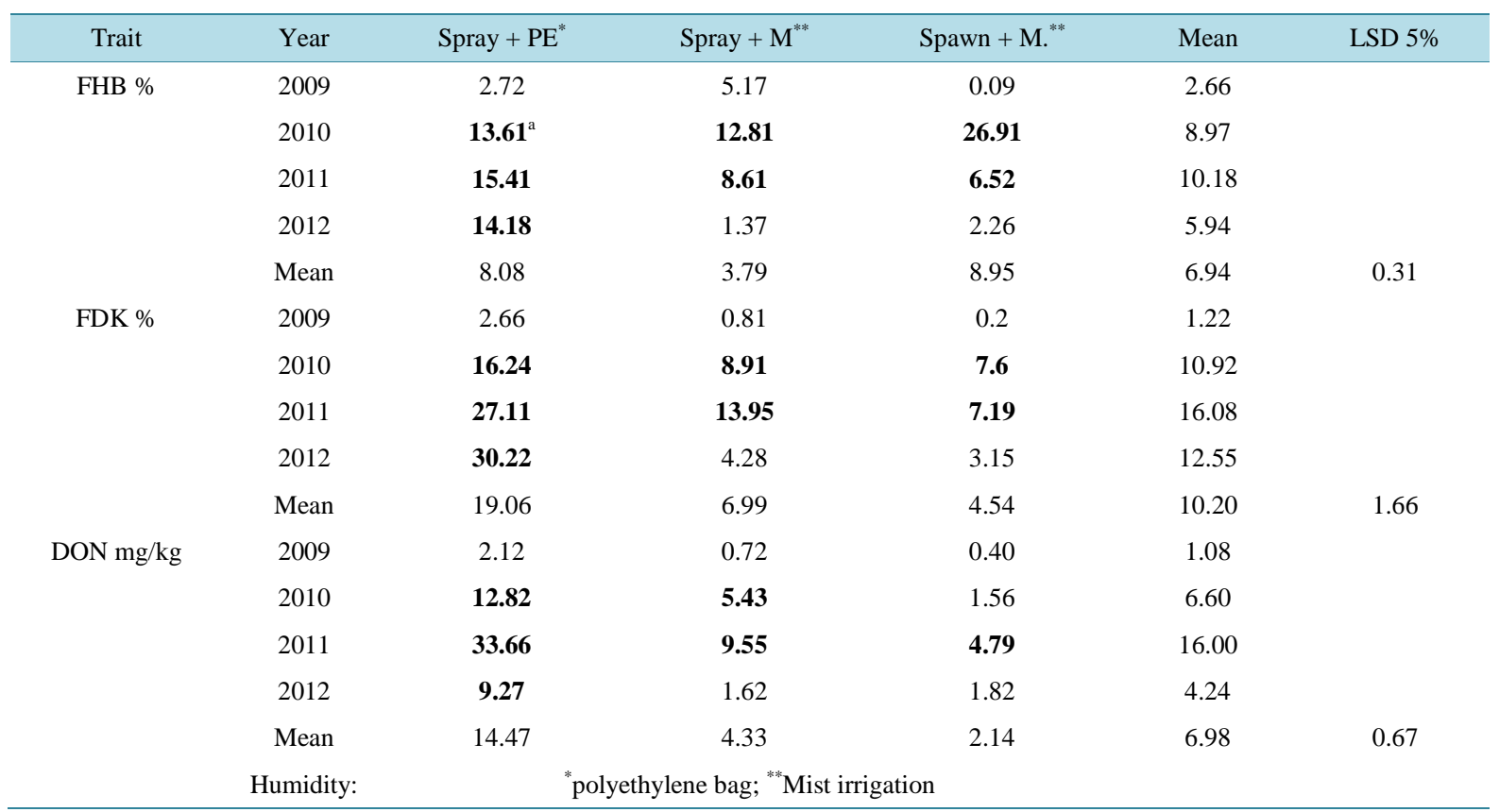

${ }^{\mathrm{a}}$ Suitable for good differentiation.

was also much lower. It seems that the high infection of the heads was rather superficial and did not invade the kernels, and the DON was even much less than what was found in 2011. The advantage of the DON contamination is clear and the spray + bag methods also give the highest indices. The values are even low for 2009, but the spray + bag were superior to other methods also this year.

The ANOVA table (Table 10) presents variance components of the FHB, FDK and DON data across years, epidemic situations and methodical approaches. As the Within/Error in the ANOVAs was significant for each trait, therefore the significance was tested for the AxBxCxD interaction instead of the Within. All main effects are highly significant indicating high differences between genotypes, methods, years and epidemic severities. The genotype main effect and the interactions containing the genotype effect are highlighted by bold printing. It is important that the two-way interactions are significantly smaller than the main genotype effect that refers to a rather high stability of a variety reaction in different environments. The three way interactions are even lower, several of them not being significant at all. The difference between them and the genotype effect is also highly significant. This means that the genotype reactions are rather stable, even the year, method and epidemiological severity provide alone much higher numbers. Their practical significance of the three and four-way interactions is near zeros, even some are higher than the LSD 5\% limit.

\subsection{Relationships between Traits, the Role of Resistance Components}

The basic resistance trait is the visual FHB disease index. It correlates with FDK\% as a mean function across all epidemic situations with a correlation value of $r=0.54$ (Figure 2). We see two deviations from the regression line. We have 12 genotypes that have significantly smaller FDK values than predicted by the regression line (LSD 5\%) value indicated as resistance to kernel infection (kernel resistance). However, we have also 11 genotypes that have significantly stronger infection than what we predicted according to the regression function. This is the extra susceptibility to kernel infection (kernel susceptibility). This means that more than $57 \%$ of the genotypes deviate either upwards or downwards from the regression line, and only $43 \%$ were not significantly different from their predicted values on the regression line. The conclusion is that based on the FHB index, no accurate prediction can be made for FDK, since about 50\% of the genotypes are off-type. Of course, based on FHB data we cannot predict which genotype will react according to this model.

When we look the FHB and DON regression (Figure 3) we see a very similar picture compared to what we 
Table 10. ANOVA for the traits in the comparison of inoculation method trial, 2009-2012.

\begin{tabular}{|c|c|c|c|c|c|c|c|}
\hline \multirow{2}{*}{$\begin{array}{l}\text { Source of } \\
\text { variance }\end{array}$} & \multirow[b]{2}{*}{ df } & \multicolumn{2}{|c|}{ FHB } & \multicolumn{2}{|c|}{ FDK } & \multicolumn{2}{|c|}{ DON } \\
\hline & & MQ & $\mathrm{F}_{\mathrm{AxBxC}}{ }^{*}$ & MQ & $\mathrm{F}_{\mathrm{AxBxC}}{ }^{*}$ & MQ & $\mathrm{F}_{\mathrm{AxBxC}}{ }^{*}$ \\
\hline Genotype A & 39 & 1431.5 & $80.8 a$ & 1483.2 & $18.7 a$ & 770.8 & $10.2 \mathrm{a}$ \\
\hline Method B & 2 & 7935.7 & $447.8 \mathrm{a}$ & $86,944.5$ & 1083.1a & $55,531.5$ & $737.2 \mathrm{a}$ \\
\hline Severity C & 3 & $19,092.1$ & 1077.4a & $42,977.2$ & $535.4 a$ & $24,478.2$ & $324.9 a$ \\
\hline Year D & 3 & $34,682.8$ & 1957.3a & $28,004.8$ & 348.9a & $37,747.5$ & 501.1a \\
\hline$A \times B$ & 78 & 275.4 & $15.5 a$ & 460.2 & $5.7 a$ & 309.1 & 4.1a \\
\hline$A x C$ & 117 & 104.8 & $5.9 \mathrm{a}$ & 153.9 & $1.9 a$ & 158.8 & 2.1a \\
\hline AxD & 117 & 696.8 & 39.3a & 892.2 & 11.1a & 352.1 & $4.7 \mathrm{a}$ \\
\hline $\mathrm{BxC}$ & 6 & 7408.8 & 418.1a & $20,023.4$ & $249.4 a$ & $12,087.8$ & $160.5 \mathrm{a}$ \\
\hline $\mathrm{BxD}$ & 6 & $15,830.9$ & 893.4a & $15,627.7$ & $194.7 \mathrm{a}$ & $13,680.1$ & $181.6 \mathrm{a}$ \\
\hline $\mathrm{CxD}$ & 9 & 3979.9 & $224.6 a$ & 4910.1 & $61.2 \mathrm{a}$ & 6633.9 & 88.1a \\
\hline $\mathrm{AxBxC}$ & 234 & 53.8 & $3.0 \mathrm{a}$ & 84.1 & 1.0ns & 104.9 & $1.4 \mathrm{a}$ \\
\hline AxBxD & 234 & 80.5 & $4.5 a$ & 297.2 & $3.7 \mathrm{a}$ & 133.2 & $1.8 \mathrm{a}$ \\
\hline $\mathrm{AxCxD}$ & 351 & 6.7 & $0.4 \mathrm{~ns}$ & 43.9 & $0.5 n s$ & 57.2 & $0.7 n s$ \\
\hline $\mathrm{BxCxD}$ & 18 & 61.9 & $3.5 \mathrm{a}$ & 1818.5 & $22.6 a$ & 3363.2 & $44.6 \mathrm{a}$ \\
\hline$A x B x C x D$ & 702 & 17.7 & & 80.3 & & 75.3 & \\
\hline Within & 1920 & 7.2 & & 24.7 & & 57.3 & \\
\hline Total & 3839 & & & & & & \\
\hline
\end{tabular}

a: $p=0.001, b: p=0.05, c: p=0.05$, ns = non-significant. Bold: variance sources with genotype main effect and its interactions.

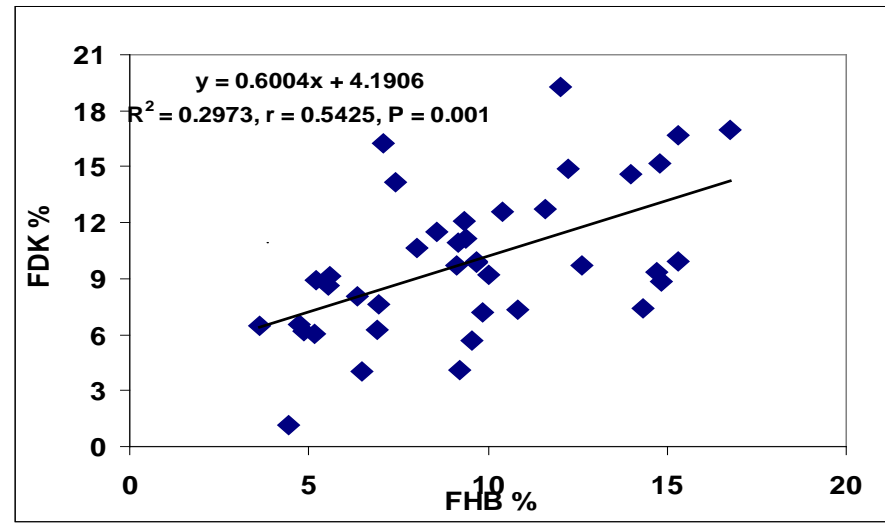

Figure 2. Regression between FHB visual symptoms and FDK, 2009-2012. Data points: mean across inoculation methods, years and isolates.

have seen for the disease index and FDK regression. The figure clearly shows that a similar portion of the genotypes has significantly more or less DON than was predicted by the regression function. When for example we have DON values between 2 and $10 \mathrm{mg} / \mathrm{kg}$ at $9 \%$ disease index, this means that DON contamination based on FHB data cannot be predicted at the exactness we would need in the breeding.

The FDK-DON comparison produced quite a different picture (Figure 4). The $r=0.8139(p=0.001)$ correlation is very closes the closest we found among the different traits. Six genotypes showed significantly higher DON contamination than the corresponding point on the regression line (termed DON susceptibility); whereas two genotypes showed significantly less DON (termed DON resistance). This is $20 \%$ of the genotypes that behave differently. The correlation coefficient without the eight genetically different off type is $\mathrm{r}=0.9303$ ( $\mathrm{p}=$ 0.001) indicating that for a number of deviation the genetic background is responsible ant not the environment or other ecological influences. The DON susceptibility is a phenomenon overlooked until now. This may cause 


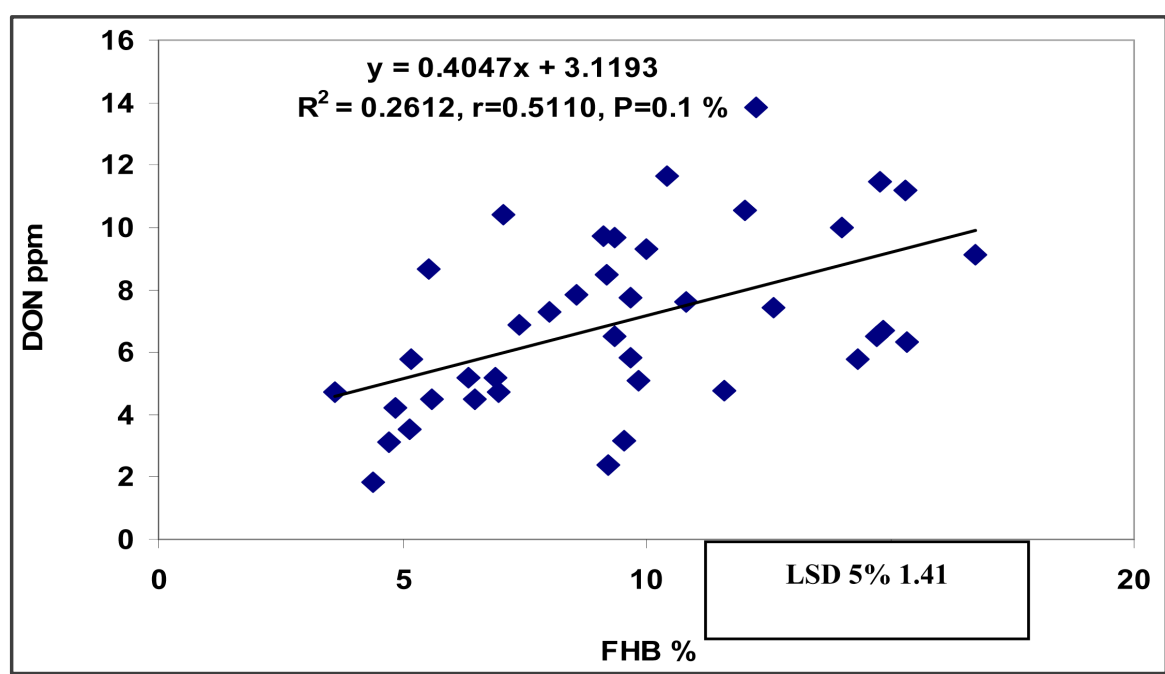

Figure 3. Regression between visual FHB data and DON contamination, 2009-2012. Data points: mean across inoculation methods, years and isolates.

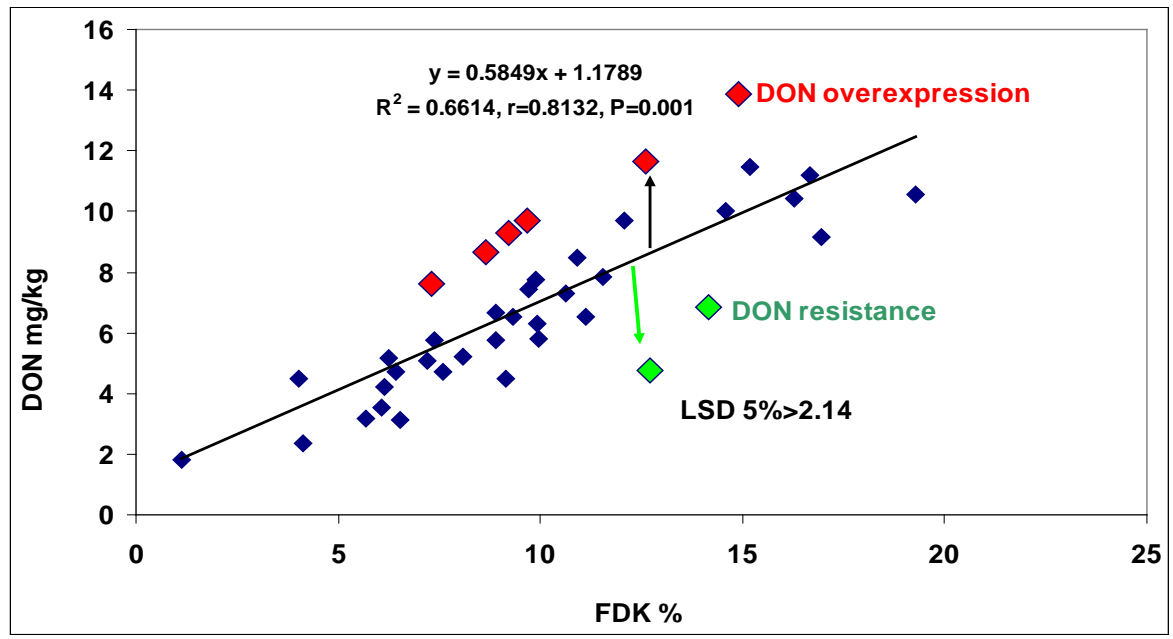

Figure 4. Regression between FDK and DON data, 2009-2012. Data points: mean across inoculation methods, years and isolates.

serious additional food safety problem that cannot be identified from the disease index and FDK data. Additionally, without toxin measurement this safety factor cannot be detected and identified at the variety level. It is important that the deviations to DON susceptibility (overproduction) or DON resistance is genetically determined as the differences are highly significant.

To visualize the resistance types, the variety specific data for all genotypes and traits are given in Table 11. We have only eight of the 40 genotypes that have no significant deviation for any of the traits. This is only $20 \%$. It seems that the non deviating genotypes concentrate in the more resistant part of the population. We have two genotypes that have additional susceptibility to all traits tested. This is only $5 \%$ of the total. They are in the middle of the population, such genotypes were not found in the more resistant or susceptible thirds of the population. No one genotype was found with additional resistance to any of the traits. This means that $75 \%$ of the genotypes tested has diverging distribution to the kernel resistance or susceptibility and DON resistance and susceptibility. The data confirm we reported in the Figures 2-4, for kernel resistance and susceptibility the genotypes occur everywhere at a large ratio. The DON resistance/susceptibility occurs significantly less and this is more concentrated in the more susceptible half of the population tested. For the DON resistance/susceptibility the least items are found in the middle part of the population. 
Table 11. Distributions of the kernel resistance/susceptibility and DON resistance/susceptibility in the FHB resistance tests, 2009-2012. Data general means across years, inoculation methods and epidemic severities.

\begin{tabular}{|c|c|c|c|c|c|c|c|c|c|}
\hline \multirow[b]{2}{*}{ Genotypes } & \multicolumn{3}{|c|}{ FHB/FDK } & \multicolumn{3}{|c|}{ FHB/DON } & \multicolumn{3}{|c|}{ FDK/DON } \\
\hline & FDK & $\begin{array}{l}\text { FDK } \\
\text { line }^{*}\end{array}$ & Diff. & DON & $\begin{array}{l}\text { DON } \\
\text { line }^{*}\end{array}$ & Diff. & DON & DON line* & Diff. \\
\hline SzD $0016 \mathrm{~S}$ & 6.44 & 6.36 & 0.07 & 4.72 & 4.58 & 0.14 & 4.72 & 4.95 & -0.22 \\
\hline Rst/NB b & 1.13 & 6.85 & -5.72 & 1.82 & 4.91 & -3.09 & 1.82 & 1.84 & -0.02 \\
\hline $\begin{array}{c}\mathrm{Zu} / / \mathrm{Ré} / \mathrm{NB} / 5 / \mathrm{DH} \mathrm{Kö/In/4/} \\
\text { Sgv/3/GT/Pdj2//Uhrt }\end{array}$ & 6.52 & 7.02 & -0.50 & 3.11 & 5.03 & -1.92 & 3.11 & 4.99 & -1.88 \\
\hline MIDAS & 6.16 & 7.11 & -0.95 & 4.21 & 5.08 & -0.87 & 4.21 & 4.78 & -0.57 \\
\hline SzD 5319 & 6.06 & 7.28 & -1.21 & 3.52 & 5.20 & -1.68 & 3.52 & 4.72 & -1.21 \\
\hline SzD 6401 & 8.91 & 7.31 & 1.60 & 5.78 & 5.22 & 0.56 & 5.78 & 6.39 & -0.61 \\
\hline SzD 18364 (B-18364) & 8.67 & 7.51 & 1.15 & 8.65 & 5.36 & 3.29 & 8.65 & 6.25 & 2.41 \\
\hline SzD 4511 & 9.15 & 7.55 & 1.61 & 4.51 & 5.38 & -0.87 & 4.51 & 6.53 & -2.02 \\
\hline SzD 5501 & 8.07 & 8.00 & 0.07 & 5.20 & 5.69 & -0.49 & 5.20 & 5.90 & -0.71 \\
\hline GALLUS (SzD 8583) & 4.02 & 8.08 & -4.07 & 4.50 & 5.74 & -1.24 & 4.50 & 3.53 & 0.97 \\
\hline SzD 0016 F & 6.23 & 8.33 & -2.10 & 5.19 & 5.91 & -0.72 & 5.19 & 4.83 & 0.36 \\
\hline SzD 5066 & 7.61 & 8.37 & -0.77 & 4.72 & 5.94 & -1.22 & 4.72 & 5.63 & -0.91 \\
\hline SzD 5275 & 16.27 & 8.43 & 7.84 & 10.43 & 5.98 & 4.45 & 10.43 & 10.69 & -0.26 \\
\hline GK HATTYU & 14.14 & 8.64 & 5.50 & 6.86 & 6.12 & 0.74 & 6.86 & 9.45 & -2.60 \\
\hline GK PETUR & 10.61 & 9.00 & 1.61 & 7.31 & 6.36 & 0.95 & 7.31 & 7.39 & -0.08 \\
\hline SzD 5377 & 11.53 & 9.33 & 2.20 & 7.83 & 6.58 & 1.25 & 7.83 & 7.92 & -0.09 \\
\hline SzD 6701 & 9.69 & 9.66 & 0.03 & 9.71 & 6.81 & 2.90 & 9.71 & 6.85 & 2.86 \\
\hline GK HUNYAD & 10.93 & 9.71 & 1.22 & 8.46 & 6.84 & 1.62 & 8.46 & 7.57 & 0.89 \\
\hline $\mathrm{Zu} / / \mathrm{Ré} / \mathrm{Nb}$ a & 4.13 & 9.73 & -5.60 & 2.37 & 6.85 & -4.48 & 2.37 & 3.59 & -1.22 \\
\hline GK SZALA & 12.06 & 9.80 & 2.26 & 9.68 & 6.90 & 2.78 & 9.68 & 8.23 & 1.45 \\
\hline RAINER & 11.12 & 9.81 & 1.30 & 6.53 & 6.91 & -0.38 & 6.53 & 7.68 & -1.15 \\
\hline $\mathrm{Zu} / / \mathrm{Ré} / \mathrm{Nb}$ a & 5.68 & 9.92 & -4.24 & 3.15 & 6.98 & -3.83 & 3.15 & 4.50 & -1.35 \\
\hline GK HOLLÓ & 9.94 & 9.99 & -0.05 & 5.80 & 7.03 & -1.23 & 5.80 & 6.99 & -1.19 \\
\hline SzD 6626 & 9.88 & 10.00 & -0.11 & 7.76 & 7.03 & 0.73 & 7.76 & 6.96 & 0.80 \\
\hline Ttj/RC103/3/Sgv/NB//MM/Sum3 & 7.22 & 10.10 & -2.88 & 5.09 & 7.10 & -2.01 & 5.09 & 5.40 & -0.31 \\
\hline SzD 5205 & 9.21 & 10.20 & -0.99 & 9.31 & 7.17 & 2.14 & 9.31 & 6.52 & 2.79 \\
\hline SzD 7257 & 12.60 & 10.45 & 2.15 & 11.64 & 7.34 & 4.30 & 11.64 & 8.55 & 3.09 \\
\hline $\mathrm{Rst} / \mathrm{Nb}$ a & 7.32 & 10.69 & -3.37 & 7.60 & 7.50 & 0.10 & 7.60 & 5.46 & 2.14 \\
\hline BALATON & 12.70 & 11.15 & 1.55 & 4.75 & 7.81 & -3.06 & 4.75 & 8.61 & -3.86 \\
\hline SzD 6515 & 19.26 & 11.41 & 7.86 & 10.56 & 7.98 & 2.57 & 10.56 & 12.45 & -1.89 \\
\hline GK KAPOS & 14.90 & 11.54 & 3.37 & 13.86 & 8.07 & 5.79 & 13.86 & 9.90 & 3.96 \\
\hline Be/SK 48.21//FHB 142 & 9.71 & 11.77 & -2.05 & 7.43 & 8.23 & -0.79 & 7.43 & 6.86 & 0.57 \\
\hline SzD 5417 & 14.59 & 12.59 & 2.00 & 10.01 & 8.78 & 1.22 & 10.01 & 9.72 & 0.29 \\
\hline GK FÉNY & 7.39 & 12.79 & -5.41 & 5.78 & 8.92 & -3.14 & 5.78 & 5.50 & 0.28 \\
\hline GK BÉKÉS & 9.32 & 13.03 & -3.71 & 6.53 & 9.08 & -2.55 & 6.53 & 6.63 & -0.10 \\
\hline GK KALÁSZ & 15.17 & 13.08 & 2.09 & 11.47 & 9.11 & 2.36 & 11.47 & 10.05 & 1.42 \\
\hline Attila/3/Sgv/NB//MM/Sum2 & 8.88 & 13.11 & -4.23 & 6.68 & 9.13 & -2.45 & 6.68 & 6.37 & 0.31 \\
\hline GK PIACOS & 16.65 & 13.38 & 3.27 & 11.18 & 9.31 & 1.87 & 11.18 & 10.92 & 0.26 \\
\hline GK CSILLAG & 9.94 & 13.39 & -3.46 & 6.32 & 9.32 & -3.00 & 6.32 & 6.99 & -0.67 \\
\hline GK ÉLET & 16.96 & 14.24 & 2.72 & 9.15 & 9.89 & 0.75 & 9.18 & 11.10 & -1.92 \\
\hline Mean & 9.92 & 9.92 & 0.00 & 6.98 & 6.98 & 0.00 & 6.98 & 6.98 & 0.00 \\
\hline LSD $5 \%$ & & & 1.41 & & & 2.14 & & & 2.14 \\
\hline -Resistance & & uscepti & & & GeI & ypes wit & out any & eviation & \\
\hline
\end{tabular}

* Line: counted data point value on the regression line. 


\subsection{Stability of Resistance}

The measured stability of resistance to different traits is given in Table 11. The stability index is the b value of the linear regression function $y=a+b x$. The means for all traits are $b=1.000$, from Eberhart and Russel (58). When this number is less than one, the stability is better than the mean of the population. However, the $b$ values for the different traits may vary strongly. For FHB the best (smallest) value stability value is 0.45 , and the highest [worst) is 1.64. For FDK the variation is between 0.09 and 1.37 and for DON ranges from 0.23 to 2.18. The means for genotypes are between 0.27 and 1.57 , close to a six-fold difference. It is important that the stability found for the FHB index does not say much about the stability of the other traits. For example the Zu//Ré/NB a line from our breeding program has an FHB value of 0.94, and an FDK value of 0.59 , and only a value of 0.32 for DON. Its sister line $\mathrm{Zu} / / \mathrm{Re} / \mathrm{NB} \mathrm{b}$ is better, but the differences between traits are even larger, with an FHB of 0.50, 1.64 an FDK of 0.09 and a DON value of 0.27 . For the least stable genotypes the $b$ values are above one, the highest mean has an SZD value of SzD5417 with an FHB value of 1.64, an FDK value of 1.37 and a DON value of 1.63. The correlations between stability data show the same tendency that we outlined for the regressions and correlations in Figures 2-4. The FHB-FDK stability data have a correlation of $r=0.4511$, the FHBDON has a correlation of $r=0.55(p=0.001)$, and the FDK-DON has a correlation of $r=0.66(p=0.001)$. All values are significant at $p=0.001$. It is clear that the stability of individual genotypes for different traits is not the same. Therefore we counted the correlations between them to see, whether some conclusion can be drawn from this or not. It is remarkable that the mean of the three stability indexes correlates the least with FHB $(\mathrm{r}=$ $0.78, p=0.001)$, better with FDK $(r=0.81, p=0.001)$, and best with DON $(r=0.92, p=0.001)$, all significant at $\mathrm{p}=0.001$, the increasing trend to $\mathrm{DON}$ is very clear.

Where does this stability come from? When we see the correlations between general means for the given trait and the stability indexes (Table 12), the FHB-stability index has a correlation value of $r=0.90, r=0.79$ for FDK, and $r=0.89$ for DON, all significant at $p=0.001$. This means that with several exceptions higher resistance correlates well with higher stability, but smaller deviations under very different epidemic conditions are possible.

As the stability index measured by the "b" value of the linear regression in sensu Eberhart and Russel [58] differs largely, we show the differences between the two most and least stable genotypes (Figure 5). For FHB the maximum visual FHB index in GK Kapos is $70 \%$, which is twice as large as the value for RSt/NB b. We see also variation in the data in that some epidemics have a higher index in RSt/NB b than in GK Kapos.

In FDK, however, the difference is more striking. In GK Kapos a very high (up to 90\%) FDK value was recorded. All data for resistant lines are close to the x-axis with the most infected cultivar being only $10 \%$. The difference in DON is also striking, for GK Kapos $143 \mathrm{mg} / \mathrm{kg}$ was the maximum value recorded, whereas RSt/NB b had the worst value at $18 \mathrm{mg} / \mathrm{kg}$. In 23 cases the DON concentration was lower than the EU limit of $1.25 \mathrm{mg} / \mathrm{kg}$, for GK Kapos only 5 such cases were found. The very popular intermediately resistant GK Csillag had 11 cases lower than the EU limit with a maximum value of $65 \mathrm{mg} / \mathrm{kg}$.

\section{Discussion}

\subsection{Comparison of the Testing Methods}

The three methods outlined in this paper have a common background. This is clear for the two spraying variants, but the spawn method also belongs here as the basis of the method is that the inoculum will be delivered from inoculated maize grain or stalk residues naturally to the heads. In the first two methods the timing of inoculation is given and it can be performed for the differently flowering genotypes at the same developmental stage. Holzapfel et al. [61] applied repeated spray inoculation to secure infection for all ripening groups. In a resistance test four inoculation times were applied to secure infection for different ripening groups [4]. They did not use misting as the locations were supplied with enough rain during most seasons. In their tests the different number of inoculations might cause problems in comparison. In the spawn method no direct inoculation on the earswas performed, therefore the inoculation time can be regulated only to some extent by misting, in the population the infections may be generated in a very wide time range. All methods need to secure a humid environment. In the PE bag method the length of the humidity period is given, in our case 48 hrs. In the spraying + mist irrigation method different regimes work, here we followed the method of Grausgruber et al. [54] and Lemmens et al. [38] [39]. Here following inoculation two days interrupted misting was applied during the daytime to keep the heads 
Table 12. Stability indexes for the 40 genotypes at 36 epidemic severities, 2009-2012. Numbers: "b” value of the linear regression function between mean of 36 epidemic situations and the individual data of individual genotypes.

\begin{tabular}{|c|c|c|c|c|}
\hline \multirow{2}{*}{ Genotypes } & \multicolumn{3}{|c|}{ Traits } & \multirow{2}{*}{ Mean } \\
\hline & FHB & FDK & DON & \\
\hline Rst/NB b & 0.50 & 0.09 & 0.23 & 0.27 \\
\hline SzD 5319 & 0.50 & 0.73 & 0.50 & 0.58 \\
\hline Zu//Ré/NB/5/DH Kö/In/4/Sgv/3/GT/Pdj2//Uhrt & 0.45 & 0.91 & 0.39 & 0.58 \\
\hline SzD $0016 \mathrm{~S}$ & 0.54 & 0.70 & 0.61 & 0.61 \\
\hline $\mathrm{Zu} / / \mathrm{Ré} / \mathrm{NB}$ a & 0.94 & 0.59 & 0.32 & 0.62 \\
\hline MIDAS & 0.53 & 0.77 & 0.70 & 0.67 \\
\hline SzD 4511 & 0.52 & 1.04 & 0.50 & 0.69 \\
\hline $\mathrm{Zu} / / \mathrm{Ré} / \mathrm{NB}$ b & 0.85 & 0.88 & 0.41 & 0.72 \\
\hline SzD 5501 & 0.82 & 0.83 & 0.55 & 0.73 \\
\hline GALLUS (SzD 8583) & 0.72 & 0.64 & 0.84 & 0.73 \\
\hline GK HOLLÓ & 0.93 & 0.80 & 0.57 & 0.77 \\
\hline SzD $0016 \mathrm{~F}$ & 0.75 & 0.89 & 0.83 & 0.82 \\
\hline GK PETUR & 0.89 & 0.82 & 0.91 & 0.87 \\
\hline GK BÉKÉS & 1.35 & 0.67 & 0.67 & 0.90 \\
\hline SzD 5275 & 0.81 & 1.01 & 0.88 & 0.90 \\
\hline Ttj/RC103/3/Sgv/NB//MM/Sum3 & 0.98 & 1.00 & 0.76 & 0.91 \\
\hline Rst/NB a & 1.12 & 0.58 & 1.08 & 0.93 \\
\hline SzD 18364 (B-18364) & 0.91 & 0.77 & 1.17 & 0.95 \\
\hline SzD 5066 & 0.86 & 1.06 & 0.97 & 0.96 \\
\hline SzD 6401 & 0.71 & 1.19 & 1.01 & 0.97 \\
\hline GK CSILLAG & 1.09 & 1.06 & 0.96 & 1.04 \\
\hline Attila/3/Sgv/NB//MM/Sum3 & 1.21 & 1.04 & 0.92 & 1.05 \\
\hline BALATON & 1.00 & 1.32 & 0.89 & 1.07 \\
\hline GK HATTYU & 0.90 & 1.35 & 1.11 & 1.12 \\
\hline SzD 5377 & 0.98 & 1.32 & 1.08 & 1.13 \\
\hline SzD 6626 & 1.19 & 1.01 & 1.19 & 1.13 \\
\hline RAINER & 1.02 & 1.26 & 1.14 & 1.14 \\
\hline GK KALÁSZ & 1.30 & 1.13 & 0.99 & 1.14 \\
\hline GK ÉLET & 1.53 & 0.98 & 0.93 & 1.15 \\
\hline GK PIACOS & 1.27 & 0.98 & 1.26 & 1.17 \\
\hline GK FÉNY & 1.45 & 1.16 & 0.96 & 1.19 \\
\hline GK HUNYAD & 1.07 & 1.34 & 1.27 & 1.23 \\
\hline GK SZALA & 0.99 & 1.33 & 1.37 & 1.23 \\
\hline Be/SK 48.21//FHB 143 & 1.57 & 1.21 & 0.98 & 1.25 \\
\hline SzD 6701 & 1.32 & 1.06 & 1.49 & 1.29 \\
\hline SzD 5205 & 1.40 & 1.13 & 1.70 & 1.41 \\
\hline SzD 6515 & 1.11 & 1.47 & 1.87 & 1.49 \\
\hline SzD 5417 & 1.64 & 1.37 & 1.63 & 1.55 \\
\hline SzD 7257 & 1.22 & 1.34 & 2.16 & 1.57 \\
\hline GK KAPOS & 1.06 & 1.17 & 2.18 & 1.47 \\
\hline Mean & 1.000 & 1.000 & 1.000 & 1.000 \\
\hline Correlations & FHB & FDK & DON & \\
\hline FDK & 0.45 & & & \\
\hline DON & 0.55 & 0.66 & & \\
\hline All significant at $p=0.001$ & & & & \\
\hline
\end{tabular}




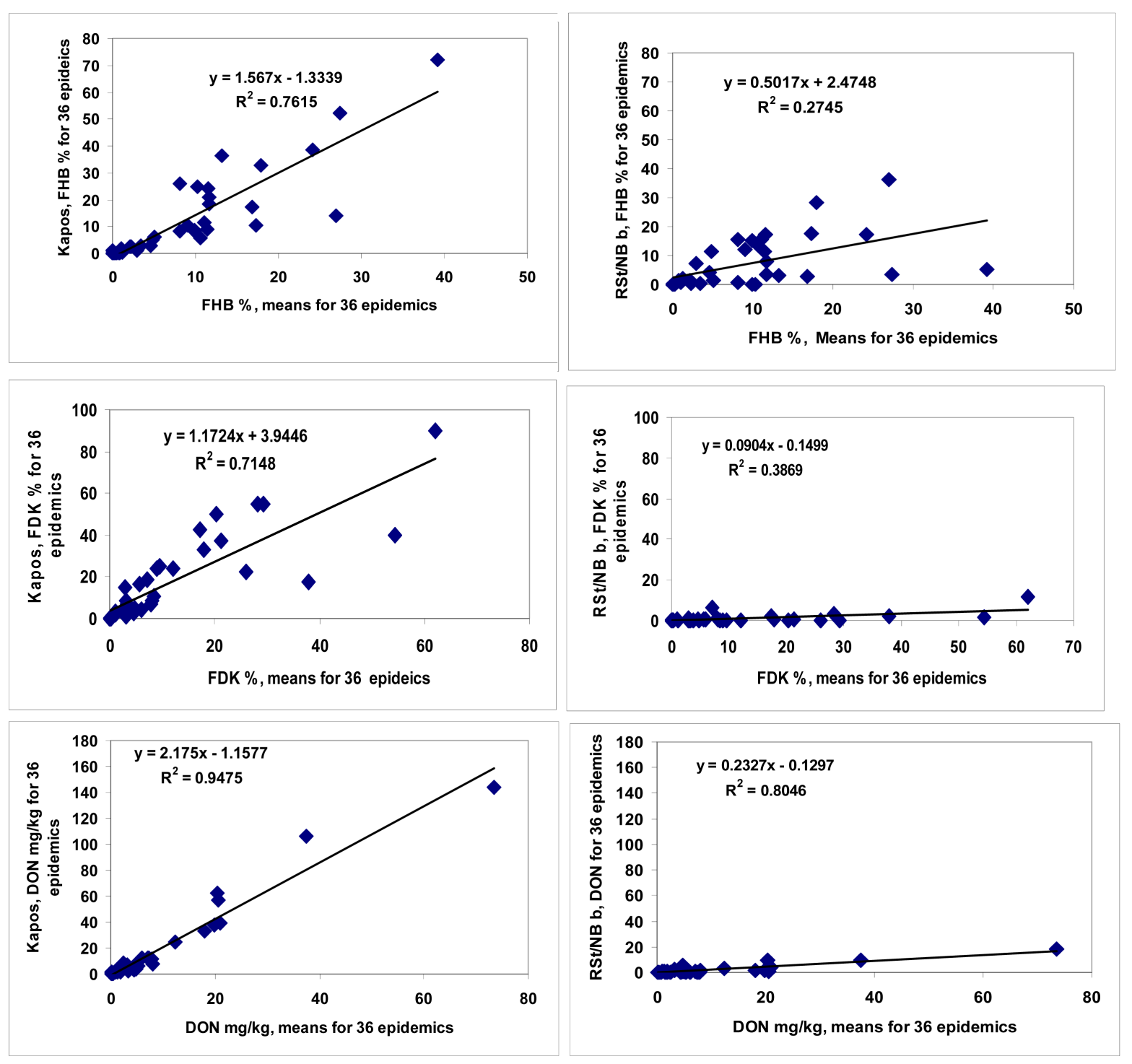

Figure 5. Comparison of the most and least stable genotypes of the cultivar set tested for all traits, 2009-2012.

wet. As different ripening groups need different methods of inoculation, the earlier inoculated genotypes receive 2 - 4 times more misting than the previously inoculated genotypes. The temperature changes during inoculation and thereafter may also cause large deviations. In a test with the Frontana/Remus population [13] we found that one year the earliest inoculated genotyped had the highest infection rate, since the weather was rather warm during inoculation. Next year the case was the opposite, with the latest genotypes being the most infected. Such cases make it possible to identify resistance QTLs as a result of earliness or lateness.

We have to mention here the strong need of breeders to imitate natural infection. Great epidemics reveal a significant variety of differences. However, when the infection period associated with a large rain is short, as normally is the case; later or earlier cultivars may prove to be symptomless. During other seasons, however, they are much more jeopardized. A severe natural epidemic in the Szeged nursery comes once every ten years when an acceptable selection is possible. For this reason the use of artificial inoculation methods is inevitable in a breeding program.

For FHB index the data show a good agreement between the three different methods and the mean FHB index data are also not very different. It means that selecting for low infection severity may be successful in a number of cases, but not in others. As methodological tests only compared FHB index values, the possible role of the other traits remained concealed. The FDK mean data present a different picture. The highest severity was found 
for the spray + bag method with $19 \%$ across 40 genotypes, the spray + misting caused $5.7 \%$ and the spawn method only $4.6 \%$. The correlations between genotype reactions are lower, with the spray + bag method correlating with the spray + misting method by $r=0.55$. The spray + bag method did not show a significant correlation with the spawn method and a medium level of correlation was found between the spray + misting method and the spawn method. The most severe DON contamination was found for the spray + bag method, 3.5 higher than the spray + misting method and seven times higher than the spawn method. The correlations were closest between the spray + bag method and the spray + misting method $r=0.67(p=0.001)$, the spray + bag method correlated with the spawn method very poorly $(r=0.30, p=0.05)$ and the two misting method overlapped better with a correlation value of $r=0.60, p=0.001$. In the ANOVA significant interaction between methods and genotypes was found, indicating the influence of the methods on the variety ranking. The genotype effect was found to be superior over double and three- and four way interactions. This is in agreement with the data of Kubo et al. [62]. Another lesson is that at higher disease index the differentiation in resistance more secure, especially at higher resistance level. For this the presented data for epidemic severity and year effect present convincing examples also for FDK and DON.

When we see the yearly variation of the data (Table 8), it becomes clear that the highest indices were gained for all traits using the spray + bag methods, from four years three were secured. The spawn method gave very high infection only once, in 2010. However, this high visual infection was not reflected in the FDK and even less in DON contamination. This year was very wet with nearly $300 \mathrm{~mm}$ of rain in May and June, and following inoculation misting was also given as no precipitation occurre4d, only before and after. It seems that the high visual infection did not reach the grains, only visual symptoms were caused. As this was valid for nearly all genotypes, except the most resistant Hungarian FHB selected lines and two Austrian genotypes (Midas and SzD 6401). We do not think that the difference between inoculation results should be the same we found here. In cooler and more humid countries the differences were less as found by Lemmens et al. 2012, personal communication). However we think that breeding institutes working on climatically very changing conditions, the spraying + bagging method will provide better data for selection.

The variances for the three traits show the response of the genotypes to different inoculation methods. At all resistance level we have genotypes which show low and high variation, thus the trait is not associated with resistance. The least susceptible genotype for FDK had a value of 2.21, and the very susceptible GK Kalász 1.10 showed nearly the same data values in all methods. However, GK Piacos with the same resistance level gave a variance of 33 and the genotype SZD 5417 had a value of 46.38. The variance for the method means was 14.59. For this reason we suggest not to look at the mean data only, but also the variance of disease expression. This feature is as important as the stability of resistance that will be discussed below.

The conclusion is that the different methods do not give an answer to the same question. The answers are more or less similar. The fhb traits differ; and the visual symptoms, FDK and DON contamination do not closely follow the same pattern. For now the DON is the most important criterion. The inland and export trade are governed by DON contamination, its limit in EU is $1.25 \mathrm{mg} / \mathrm{kg}$, in other countries it may be different. Therefore the question is not the decrease in disease index, but the decrease in DON contamination. We need therefore the trait that delivers the most reliable predictive power for DON. Of the analyzed traits it is the FDK.

\subsection{Resistance Types and Selection Criteria}

The FHB/FDK regression (Figure 2) shows only a significant, but moderate correlation value of $r=0.54(\mathrm{p}=$ 0.001). The resistance to kernel infection [24] comes from the idea that those genotypes should be considered to have a resistance type [or component) that has no significant difference in FHB value, but their FDK values differ significantly. We found that the The presence of the resistance to kernel infection was supported among others by Gaertner et al. [63], Kubo et al. [62], Sneller et al. [64]. However, during the past 20 years we realized that the criterion is not solid enough, as it might occur with some genotypes pairs where the difference is significant, however their data points are on both sides within the confidence interval, e.g. not differing significantly from the corresponding data point on the regression line. Figure 2 shows this well. The other problem is based on this assumption; the kernel resistance cannot be determined between genotypes whose FHB index shows a significant difference. For this reason, we chose a more efficient way that considers those genotypes having kernel resistance having larger difference between the counted and original FDK value than the LSD 5\%. This way we found 15 genotypes with lower FDK at a greater distance than the 1.41 value (38\%). These genotypes can be termed to have kernel resistance. 12 genotypes had a significantly higher infection than predicted based 
on the distance from the regression line +1.41 LSD 5\% value (30\%), meaning that they possess termed as kernel susceptibility. Finally 13 genotypes did not significantly differ from the values on either side of the regression line. They were deemed to have kernel resistance (Table 10).

We did not pay attention to this feature in 1995. In fact, a significant part of the population has unexpectedly high FDK data, e.g. an additional FDK susceptibility. We must say that about one third of the genotypes tested have a lower value, and one third has a higher FDK value, and only one third can be considered to have a regular response. We have to stress that behind each data point there are 192 other independent data points. Because of factorial design the data were pooled and therefore only 96 data are included in the anova analyses. For this reason we can solidly conclude that from the FHB index a precise forecast of the FDK values is not possible.

Another important issue is what the source of the lower FHB/FDK correlation is. The visual scoring was finished 22 - 26 days after inoculation. However the harvest is about 4 - 5 weeks later. In a humid preharvest time the infection can spread widely [6]. In the breeding praxis about $50 \%$ of the genotypes with low FHB index should be discarded because of their high FDK values. Since different ripening groups are involved in different ways, and genotype differences might also be present, results which diverge often may be able to be interpreted. However, there is a genetic cause: in the QTL analyses we found [13] [14] that QTLs were identified in Frontana populations being responsible for either the FHB or FDK reactions, or both. We do not know what the genetic function of the QTLs is, but QTLs with a different effect can be responsible for such deviations. So the problem has beyond environmental and other effects also a mostly unknown genetic side. We should add that the FHB/FDK relationship is not everywhere accepted. For example Anon. [65] says that there is no relationship between FDK and Fusarium infection in Canada. In farm scale conditions this might be true as at harvest the FDK and shriveled light grains are blown out, and therefore the harvested grain looks much better than we see on the field before. This does not mean that a genetic relation between FHB and FDK would not be present when well planned experiments are conducted. Wegulo et al. [66] stress the necessity of the FHB resistance, but the FDK and DON are not mentioned directly as breeding goals.

We can draw a similar conclusion for the FHB/DON relation. Figure 3 shows a similar picture compared to Figure 2. Eight genotypes showed significant reduction in DON contamination (DON resistance) and nine presented higher values, e.g. DON susceptibility, and 26 did not significantly differ from their predicted value on the regression line. The correlation between the two traits is only $r=0.51(p=0.01)$ (Table 11). So $40 \%$ of all of the genotypes are different significantly from the data point on the correspondent regression line. This ratio is rather high and has food safety consequences. This means that about $40 \%$ of the genotypes tested has a chance to partial DON resistance or DON susceptibility. Thus an accurate prediction of DON contamination based on FHB values cannot be made and breeding may have false initiatives. Therefore the DON resistance data are not suggested from the FHB/DON regression as it might be strongly misleading.

The FDK/DON regression correlates the closest among all traits $(r=0.8142, \mathrm{p}=0.001)$ (Figure 4). This is significantly better than the FHB/DON correlation $(r=0.51, p=0.001)$. Of all of the genotypes six showed higher DON production than their corresponding regression point +2.14 LSD value (DON susceptibility). Two genotypes revealed significantly less DON than predicted by the function in Figure 4 (DON resistance). This way $20 \%$ of the genotypes were significantly different from the corresponding data point on the regression line. It might be important that this way the correlation without the diverging genotypes increased to $r=0.9303$. The data clearly show that FDK has much higher power in predicting DON contamination. Therefore only the 4 FDK/DON data are suitable to say something about the DON resistance or susceptibility. However, even so, 20\% of the genotypes differ only, which was $40 \%$ in the FHB/DON relationship. Therefore food safety criteria need to rank the measurement of the DON contamination in first place, secondly the FDK and the visual symptom to third place. When looking at the data (Table 11), the kernel resistant or DON resistant genotypes seldom correlates with anything. There is only one genotype, namely GK Kapos that has additional susceptibility to all traits. A consequent resistant variant was not found for any genotype for all traits. 9 genotypes had no off type reaction, whereas the rest had 1 - 2 deviating signal out of the other three. So there is no general rule that would regulate together the resistance reactions to the different traits.

When we position the food safety in the center, the DON data are the most important. The DON data give information only about the additive DON resistance and DON susceptibility as this information could not be deciphered from the FHB index and FDK values. However, without the FHB and FDK data it cannot be known whether the DON data originate from reliable test results. Therefore they are necessary. Resistance screening will be described in more detail in the Breeding Aspects in chapter 4.5. The data are clear in the respect that the 
most important trait in DON regulation is disease resistance and FDK signifies this. The causes of the DON overproduction are as of yet unknown, we cannot draw any conclusions based on the feature being discovered only now. We think that DON resistance should be applied explicitly to cases that are different from direct disease resistance. However, even if the causes are not known genotypes with this trait can be identified and excluded from commercial production.

There are several considerations that play a role in DON regulation. We mentioned several QTLs that influence DON production in plants. The production of masked DON [27] can be responsible for DON resistance, since it decreases the amount of DON by detoxification. This activity is mostly bound to the fhb1 QTL from Sumai 3, which is rare in European wheat genotypes [27]. It is possible that several lines with this QTL are in breeding nurseries. Comparing the mean DON contamination of the 24 5A fhb1 QTL lines from the CM82036/ Remus population, with the average DON contamination of the 24 3BS (fhb1) plants we found only about $10 \%$ difference [21] This indicates the decisive role of masked DON production, so the resistance level is the decisive DON regulating agent. Miller et al. [30] reported about a toxin decomposing mechanism, but it is not clear, whether this feature is identical or related to the detoxifying mechanism described by Lemmens et al. [27]. Miller and Arnison [29] reported in Frontana a DON decomposing mechanism, but the variety has no fhb1 QTL, so another mechanism could be responsible for it. Miller and Ewen [67] found that membrane stability in Frontana can be responsible for it, but the cause of the stability should be yet determined. Toxin insensitivity was reported by Snijders [46] in wheat and by Cossette and Miller [28] in maize, but the mechanism and its significance is unknown. It seems that these mechanisms are at present knowledge rater of secondary significance. It does not mean, however that plants will be identified where these or other mechanisms will be decisive. However, we are not interested in Fusarium damaged grains at low toxin contamination. This might be all right from the point of food safety, but not suitable to produce high quality grains.

In conclusion, most of the toxin reduction can be achieved by resistance, since less infected grains contain fewer toxins, and other toxin reduction mechanisms can be present with smaller effect. The many different kinds of plant material [21] [24] [25] [33] [44] indicate that this statement seems to have solid supported.

\subsection{Resistance Expression and Epidemic Severity}

The sources in this respect are very sparse. As most papers report about tests 2 - 3 years with an isolate or mixture of isolates, there is no amount of data to draw conclusions in this practically important problem from. Of course test give sometimes high differences between years or locations, but it is not clear, how much of the difference comes from the epidemic severity, location or year. In this test this problem could be studied in a more precise way. In a given year four isolates were used with differing aggressiveness. For this an environmental interaction is much less than in tests in different years and locations.. In individual years low aggressiveness was prevalent, and the data set with very low indices, not surprisingly did not correlate always with data from higher disease pressure. But the mean values of the four years balanced this problem. In FHB the data of the low, medium and high FHB indexes correlated very closely with each other, above $r=0.90$, and only the very high FHB severity data correlated less $(r=0.58, r=0.70$ and $0.84, p=0.001)$ with the data of the most severe epidemic data indicating some sort of over-infection in some genotypes. The FDK data for different epidemic severities correlated better with each other. While the tendency was similar, the differences between severity classes were diminished. For DON only the low/very high and medium/very high severities showed a lower correlation $(\mathrm{r}=$ 0.51, $\mathrm{p}=0.01, \mathrm{r}=0.59, \mathrm{p}=0.001)$. The other correlations were between $\mathrm{r}=0.74$ and $\mathrm{r}=0.78(\mathrm{both} \mathrm{p}=0.001)$. The variances also provided important information. For example, GK Kapos for DON shows a six-fold difference with a variance of 113. The variance for means was 32. With the most resistant genotypes the variance was only 0.79 . This means that variance data that are shown for all traits provides information about the adaptation of different genotypes to different ecological and epidemiological conditions. The case is similar also for the other traits. We can even find correlation to resistance level; there are very susceptible genotypes with low variance indicating levels of high infection at different disease pressures. Therefore variance and resistance level should not be considered to be related traits.

The conclusion is that the data for different epidemic severities can be used for resistance evaluation, since the general tendencies are similar. However, a much better differentiation is needed to identify the very resistant genotypes, but this is impossible without high or very high selection pressure. Of course, lower epidemic severities may provide useful information as well as a broader picture about the nature of the cultivar reaction. How- 
ever, the real resistant genotypes can be identified only at very severe infection pressure. Sometimes we receive critic that we create epidemic severities that never happen under natural conditions. Looking the most infected fields 2010 in Southern Hungary with 100\% incidence and 60\% - 70\% severity, this argument can be forgotten. We need resistance level that gives acceptable protection also under these conditions, maybe with a fungicide application [21].

\subsection{Stability of Resistance}

The stability of traits has great importance in plant breeding. Therefore it is not by chance that yield stability was developed as a major trait in plant breeding [58]. However, not only the stability of yield is important, the significance of the resistance trait is similar. As yield, also FHB resistance is governed by many QTLs is and the infection severity and other traits can vary as yields do.

There is a nearly five-fold difference for the means of traits $(0.29-1.57)$. For FHB the rate is three-fold $(0.50$ 1.67), for FDK fifteen-fold (0.09 - 1.47) and for DON nine-fold $(0.22-2.18)$. We found that a stable phenotype for all traits is rather rare; however, there is a tendency that more resistant genotypes have lower means for the traits than highly susceptible ones. The stability in DON is the most important. Since genotype differences are far larger than the LSD 5\% value, thus it is possible to improve through by breeding. However, its testing procedure is much extended. A simple breeding line cannot be tested in many epidemic situations. We can use the close correlations between resistance and stability, so a strong selection for higher resistance will result in higher stability of the reaction of variety under different ecological and epidemic conditions. We should be aware that the different traits behave differently; therefore stability for FHB symptoms does not mean automatically the same numbers for FDK and DON.

\subsection{Breeding Aspects}

The three inoculation methods gave similar results with medium level correlations. Therefore all can be used especially in places where ecological conditions favor FHB development. For practical reasons sites like Hungary with very changing weather conditions the most reliable method was the spray and bag method. I the early generations we need powerful and less reliable methods where a spraying the field several times and adding mist irrigation can help in selection. It seems to be impossible to screen 100,000 ear to row line with the spray + bag method. For this a tractor mounted sprayer as Miedaner does [4] [40] [68] [69] is perfectly suitable. Of course, other methods are also possible. As in this early phase the FHB-DON correlations are mostly poor, a DON analysis is not the case. As FDK and DON correlates closely, in early generations the low FDK is the critical point. In later phase where possibly exact data are needed, in Hungary the spray + bag method was the most effective, in other locations it might be different. From here also the DON data will be highly reliable. But this is the case in the spraying + misting method used by Lemmens [39]. As we have no specialized races in F. graminearum and other wheat infecting Fusaria, theoretically one single isolate or a mixture would be enough. We use, however, more isolates separately in this advanced stage, because the aggressiveness of the isolates is different and disease severity can be very strongly influenced. Therefore a mean reaction is more reliable to see the resistance potential in a genotype than a to evaluate the material to a highly aggressive isolate. In the first case we underestimate the resistance, in the other an overestimation is the consequence, e.g. it significantly increases the reliability of the results. For the traits we used the DON data were the most reliable. As DON amount is the critical point of the trade and animal husbandry, and the DON is the most reliable trait, it would be easy to say, we should measure only DON. The FHB and FDK in a good resistance experiment correlate well with each other as in this test. If so, the DON values will give reliable information. When the samples come from combine harvested grains, where a large part of the light infected grains in blown out, the grain is not suitable for resistance evaluation for DO, but also not for FDK. On the other side the data will be important for the producer whether the grain is marketable or not.

Variety registration also needs updating. Natural infection is not suitable. To this we suggest the spraying + bag method, under humid conditions the Lemmens [39] method is also suitable, because these gave the most stable results under different conditions. In lack of reliable registration trials the breeding firms will not invest into testing and breeding planning as the investment will never return.

It is clear from the breeding praxis that backcrossing does not work in FHB resistance especially with low and medium effect QTLs. Yang [70] applied recurrent selection and suggested multiple-fold recurrent selection also 
in the hope that many different genes can be kept together with a higher probability. As FHB resistance is polygenic (many QTLs occur), the direct marker assistant selection is problematic, especially when no large effect QTLs we have. Wilde et al. [68] compared the efficacy of phenotypic and marker assisted selection (MAS) and showed that the phenotypic selection was twice more effective as the marker assisted one. In another test MAS was more effective [69], but plant height interfered with the Qfhs.IX-6ALQTL. LOD values of QTLs is generally low [13] [71], even in some cases higher LOD values were achieved [14]. For the reasons, the phenotypic selection will be the decisive screening method for FHB as this can integrate known and unknown QTLs with their unknown interactions.

The FDK is much more important as it correlates with DON much better. Of the FHB positive genotypes additional 50\% will be discarded. The FDK positive plants are enough to screen further to DON. By this way we will get data for the most important traits, the DON. It is also clear that the most efficient DON regulator is the disease resistance, this is the basis of the use of breeding in decreasing DON contamination. We think that other mechanisms contributing to lower DON other than resistance play mostly a lower significance. We should remark that at least a medium, normally at least an $r=0.50-0.60$ correlation is needed between FHB and FDK. This refers that the experiment was made well, so the DON data will also be informative. Remark: When methodical mistake occurs like a high wind at threshing where the light contaminated grains are blown out, the correlations will be bad, and therefore the DON value will not have any significance. In fungicide tests, however, just the remaining DON is important, but here nowbody finds close correlations between FHB and DON values.

\section{Conclusions}

It is evident that FHB resistance is race-non-specific [21] [24] [25] [33] [45] [72], therefore selection for a highly aggressive isolate will result in a higher resistance to all Fusarium species tested until now. This refers not only to the FHB symptom reduction, but to FDK and also DON. However, even being non-specific, the FHB, FDK and DON are regulated by some QTLs which may influence all traits, but other ones may influence only one or two. Ecology, disease pressure and long lasting inoculation period may also cause additional problems. Some of the most important methodical requirements were summarized by Mesterházy [73]. The native sources [46] [47] are very useful as they are adapted and easier to work with. Besides this, there are many findings describing unfamiliar sources or extraneous genes [32]. The significance of the local sources was always important, and early studies identified many intermediately or more resistant genotypes, landraces, breeding lines with superior resistance [46]. We should remark that only FHB symptoms were analyzed.

In our breeding program $F_{1}$ and $F_{2}$ plants will not be inoculated. In $F_{3}$ ear to rows (2 - 18 for a combination) the best rows will be inoculated with two independent isolates without replicates. Disease resistance to other diseases and agronomic traits are also evaluated. Thus the plants left in a resistant line provide enough seed for the next generation. Based on visual symptoms, the combinations with high disease index are automatically discarded. The selected bunches will be harvested and FDK will be evaluated. Based on this, an additional 50\% of the lines will be discarded. The best lines are harvested, here grain evaluation, yield of row, NIR analysis for wet gluten, grain hardiness and Zeleny will be checked from the yield of the non-inoculated row part or the whole yield of the selected sister lines. The material will be kept in this ear-to-row system until the homogeneity is sufficient $\left(\mathrm{F}_{4}-\mathrm{F}_{5}\right)$. Lines that are homogeneous enough will be sown on $5 \mathrm{~m}^{2}$ plots for the yield trial. From these lines a separate line will be sown for next generation FHB inoculation with two isolates without replication. The best $\mathrm{B}$ lines will go to the $\mathrm{C}$ lines (four replicated yield trial). From these two additional rows will be sown and inoculated with four isolates without replicates. The plus variants will proceed to the multilocation test. For Fusarium two double rows will be sown, again with $4-4$ isolates $(p=0.001)$ they are the same for all tests and the best run for registration three years and tested for FHB this way. DON will be measured first in C lines. Then 2 g grains from each isolate's yield will be separated and pooled for DON analysis for HPLC. This will provide a good basis for making decisions.

We are convinced that the center of the breeding work should move toward the FDK and DON as FHB symptoms are less reliable. We think that this will increase the efficiency of selection and lower DON contamination in the fields, improving significantly food safety. The variety resistance testing with artificial inoculation methods must be included in the registration process; otherwise the food safety improvement cannot be realized.

\section{Acknowledgements}

The research was conducted with the financial support of the EU MycoRed FP7 (KBBE-2007-2-5-05) and GOP- 
1.1.1-11-2012-0159 projects (National Hungarian project supported by EU). The authors welcome the kind help in English correction by Dr. Mátyás Cserháti

\section{References}

[1] Mesterházy, Á. (1977) Reaction of winter wheat varieties to four Fusarium species. Journal of Phytopathology, 90, 104-112. http://dx.doi.org/10.1111/j.1439-0434.1977.tb03224.x

[2] McMullen, M., Jones, R. and Gallenberg, D. (1997) Scab of Wheat and Barley: A Re-Emerging Disease of Devastating Impact. Plant Disease, 81, 1340-1348. http://dx.doi.org/10.1094/PDIS.1997.81.12.1340

[3] McMullen, M., Bergstrom G., De Wolf, E., Dill-Macky, R., Hershman, D., Shaner, G. and Van Sanford, D. (2012) A Unified Effort to Fight an Enemy of Wheat and Barley: Fusarium Head Blight. Plant Disease, 96, 1712-1728. http://dx.doi.org/10.1094/PDIS-03-12-0291-FE

[4] Miedaner, T., Wilde , F., Steiner, B., Buerstmayr, H., Korzun, V. and Ebmeyer, E. (2006) Stacking Quantitative Trait loci (QTL) for Fusarium Head Blight Resistance from Non-Adapted Sources in an European Elite Spring Wheat Background and Assessing Their Effects on Deoxynivalenol (DON) Content and Disease Severity. Theoretical and Applied Genetics, 112, 562-569. http://dx.doi.org/10.1007/s00122-005-0163-4

[5] Mesterházy, Á., Bartók, T. and Lamper, C. (2003) Influence of Wheat Cultivar, Species of Fusarium, and Isolate Aggressiveness on the Efficacy of Fungicides for Control of Fusarium Head Blight. Plant Disease, 87, 1107-1115. http://dx.doi.org/10.1094/PDIS.2003.87.9.1107

[6] Mesterházy, Á., Tóth, B., Varga, M., Bartók, T., Szabó-Hevér, Á., Farády, L. and Lehoczki-Krsjak, S. (2011) Role of Fungicides, of Nozzle Types, and the Resistance Level of Wheat Varieties in the Control of Fusarium Head Blight and Deoxynivalenol. Toxins, 3, 1453-1483. http://dx.doi.org/10.3390/toxins3111453

[7] Lehoczki-Krsjak, S., Szabó-Hevér, Á., Tóth, B., Kótai, C., Bartók, T., Varga, M., Farády, L. and Mesterházy, Á. (2010) Prevention of Fusarium mycotoxin Contamination by Breeding and Fungicide Application in Wheat. Food Additives \& Contaminants: Part A, 27, 616-628. http://dx.doi.org/10.1080/19440041003606144

[8] Lehoczki-Krsjak, S., Varga, M., Szabó-Hevér, Á. and Mesterházy, Á. (2013) Translocation and Degradation of Tebuconazole and Prothioconazole in Wheat in the Most Fusarium-Susceptible Phenophase. Pest Management Science, 69, 1216-1224.

[9] Lehoczki-Krsjak, S., Varga, M. and Mesterházy, Á. (2015) Distribution of Prothioconazole and Tebuconazole between Wheat Ears and Flag Leaves Following Fungicide Spraying with Different Nozzle Types at Flowering. Pest Management Science, 71, 105-113. http://dx.doi.org/10.1002/ps.3774

[10] Paul, P.A., Lipps, P.E., Hershman, D.E., McMullen, M.P., Draper, M.A. and Madden, L.V. (2008) Efficacy of Triazole-Based Fungicides for Fusarium Head Blight and Deoxynivalenol Control in Wheat: A Multivariate Meta-Analysis. Phytopathology, 98, 999-1011. http://dx.doi.org/10.1094/PHYTO-98-9-0999

[11] Juroszek, P. and von Tiedemann, A. (2013) Climate Change and Potential Future Risks through Wheat Diseases: A Review. European Journal of Plant Pathology, 136, 21-33. http://dx.doi.org/10.1007/s10658-012-0144-9

[12] Buerstmayr, H, Ban, T. and Anderson J.A. (2009) QTL Mapping and Marker-Assisted Selection for Fusarium Head Blight Resistance in Wheat: A Review. Plant Breeding, 128, 1-26. http://dx.doi.org/10.1111/j.1439-0523.2008.01550.x

[13] Szabó-Hevér, Á., Lehoczki-Krsjak, S., Tóth, B., Purnhauser, L., Buerstmayr, H., Steiner, B. and Mesterházy, Á. (2012) Identification and Validation of Fusarium Head Blight and Fusarium Damaged Kernel QTL in the Frontana/Remus DH Mapping Population. Canadian Journal of Plant Pathology, 34, 224-238. http://dx.doi.org/10.1080/07060661.2012.676571

[14] Szabó-Hevér, A., Lehoczki-Krsjak, S., Varga, M., Purnhauser, L., Pauk, J., Lantos, C. and Mesterhazy, A. (2014) Differential Influence of QTL Linked to Fusarium Head Blight, Fusarium-Damaged Kernel, Deoxynivalenol Contents and Associated Morphological Traits in a Frontana-Derived Wheat Population. Euphytica, 200, 9-26. http://dx.doi.org/10.1007/s10681-014-1229-7

[15] Draeger, R., Gosman, N., Steed, A., Chandler, E., Thomsett, M., Srinivasachary, Schondelmaier, J., Buerstmayr, H., Lemmens, M., Schmolke, M., Mesterházy, A. and Nicholson P. (2007) Identification of QTLs for Resistance to Fusarium Head Blight, DON Accumulation and Associated Traits in the Winter Wheat Variety Arina. Theoretical and Applied Genetics, 115, 617-625. http://dx.doi.org/10.1007/s00122-007-0592-3

[16] Paillard, S., Schnurbusch, T., Tiwari, R., Messmer, M., Winzeler, M., Keller, B. and Schachermayr, G. (2004) QTL Analysis of Resistance to Fusarium Head Blight in Swiss Winter Wheat (Triticum aestivum L.). Theoretical and Applied Genetics, 109, 323-332. http://dx.doi.org/10.1007/s00122-004-1628-6

[17] Semagn, K., Bjørnstad, A., Skinnes, H., Marøy, A.G., Tarkegne, Y. and William, M. (2006) Distribution of DArT, AFLP, and SSR Markers in a Genetic Linkage Map of a Doubled-Haploid Hexaploid Wheat Population. Genome, 49, 
545-555. http://dx.doi.org/10.1139/G06-002

[18] Anderson, J.A., Stack, R.W., Liu, S., Waldron, B.L., Fjeld, A.D., Coyne, C., Moreno-Sevilla, B., Fetch, J.M., Song, Q.J., Cregan, P.B. and Frohberg, R.C. (2001) DNA Markers for Fusarium Head Blight Resistance QTLs Its Two Wheat Populations. Theoretical and Applied Genetics, 102, 1164-1168. http://dx.doi.org/10.1007/s001220000509

[19] Buerstmayr, H., Lemmens, M., Hartl, L., Doldi, L., Steiner, B., Stierschneider, M. and Ruckenbauer, P. (2002) Molecular Mapping of QTLs for Fusarium Head Blight Resistance in Spring Wheat. I. Resistance to Fungal Spread (Type II Resistance). Theoretical and Applied Genetics, 104, 84-91. http://dx.doi.org/10.1007/s001220200009

[20] Buerstmayr, H., Steiner, B., Hartl, L., Griesser, M., Angerer, N., Lengauer, D., Miedaner, T., Schneider, B. and Lemmens, M. (2003) Molecular Mapping of QTLs for Fusarium Head Blight Resistance in Spring Wheat. II. Resistance to Fungal Penetration and Spread. Theoretical and Applied Genetics, 107, 503-508. http://dx.doi.org/10.1007/s00122-003-1272-6

[21] Mesterházy, Á., Buerstmayr, H., Tóth, B., Lehoczki-Krsjak, S., Szabó-Hevér, Á. and Lemmens, M. (2007) An Improved Strategy for Breeding FHB Resistant Wheat Must Include Type I Resistance. In: Clear, R., Ed., Proc. of the 5th Canadian Workshop on Fusarium Head Blight, Delta Winnipeg, 27-30 November 2007, 51-66.

[22] Liu, Z.Z. and Wang, Z.Y. (1991) Improved Resistance in China: Sources of Resistance and Problems. In: Saunders, D.A., Ed., Wheat for the Nontraditional, Warm Areas, CIMMYT, Mexico D.F., 178-188.

[23] del Blanco, I.A., Frohberg, R.C., Stack, R.W., Berzonsky, W.A. and Kianian, S.F. (2003) Detection of QTL Linked to Fusarium Head Blight Resistance in Sumai 3-Derived North Dakota Bread Wheat Lines. Theoretical and Applied Genetics, 106, 1027-1031.

[24] Mesterházy, Á. (1995) Types and Components of Resistance against Fusarium Head Blight of Wheat. Plant Breeding, 114, 377-386. http://dx.doi.org/10.1111/j.1439-0523.1995.tb00816.x

[25] Mesterházy, Á., Bartók, T., Mirocha, C.M. and Komoróczy, R. (1999) Nature of Resistance of Wheat to Fusarium Head Blight and Deoxynivalenol Contamination and Their Consequences for Breeding. Plant Breeding, 118, 97-110. http://dx.doi.org/10.1046/j.1439-0523.1999.118002097.x

[26] Bai, G.-H., Plattner, R., Desjardins, A., Kolb, F. and McIntosh, R.A. (2001) Resistance to Fusarium Head Blight and Deoxynivalenol Accumulation in Wheat. Plant Breeding, 120, 1-6. http://dx.doi.org/10.1046/j.1439-0523.2001.00562.x

[27] Lemmens, M., Scholz, U., Berthiller, F., Dall’Asta, C., Koutnik, A., Schuhmacher, R., Adam, G., Buerstmayr, H., Mesterhazy, A., Krska, R. and Ruckenbauer, P. (2005) The Ability to Detoxify the Mycotoxin Deoxynivalenol CoLocalizes with a Major QTL for Fusarium Head Blight Resistance in Wheat. Molecular Plant-Microbe Interactions, 18, 1318-1324. http://dx.doi.org/10.1094/MPMI-18-1318

[28] Cossette, F. and Miller, J.D. (1995) Phytotoxic Effect of Deoxynivalenol and Gibberella Ear Rot Resistance of Corn. Natural Toxins, 3, 383-388. http://dx.doi.org/10.1002/nt.2620030510

[29] Miller, J.D. and Arnison, P.G. (1986) Degradation of Deoxynivalenol by Suspension Cultures of the Fusarium Head Blight Resistant Wheat Cultivar Frontana. Canadian Journal of Plant Pathology, 8, 147-150. http://dx.doi.org/10.1080/07060668609501818

[30] Miller, J.D., Young, J. and Sampson, D.R. (1985) Deoxynivalenol and Fusarium Head Blight Resistance in Spring Cereals. Journal of Phytopathology, 113, 359-367. http://dx.doi.org/10.1111/j.1439-0434.1985.tb04837.x

[31] Snijders, C.H.A. (1994) Breeding for Resistance to Fusarium in Wheat and Maize. In: Miller, J.D. and Trenholm, H.L., Eds., Mycotoxins in Grain Compounds Other Than Aflatoxin, Eagan Press, St. Paul, 37-58.

[32] Mesterházy, Á. (2003) Breeding Wheat for Fusarium Head Blight Resistance in Europe. In: Leonard, K.J. and Bushnell, W.R., Eds., Fusarium Head Blight of Wheat and Barley, APS Press, St. Paul, 211-240.

[33] Mesterházy, Á., Bartók, T., Kászonyi, G., Varga, M., Tóth, B. and Varga, J. (2005) Common Resistance to Different Fusarium spp. Causing Fusarium Head Blight in Wheat. European Journal of Plant Pathology, 112, 267-281. http://dx.doi.org/10.1007/s10658-005-2853-9

[34] Zwart, R.S., Muylle, H., van Bockstaele, E. and Roldán-Ruiz, I. (2008) Evaluation of Genetic Diversity of Fusarium Head Blight Resistance in European Winter Wheat. Theoretical and Applied Genetics, 117, 813-828. http://dx.doi.org/10.1007/s00122-008-0822-3

[35] Dill-Macky, R. (2003) Inoculation Methods and Evaluation of Fusarium Head Blight Resistance in Wheat. In: Leonard, K.J. and Bushnell, W.R., Eds., Fusarium Head Blight in Wheat and Barley, APS Press, St. Paul, 184-210.

[36] Schroeder, H.W. and Christensen, J.J. (1963) Factors Affecting Resistance of Wheat to Scab Caused by Gibberella zeae. Phytopathology, 53, 831-838.

[37] Lemmens, M., Buerstmayr, H. and Ruckenbauer, P. (1993) Variation in Fusarium Head Blight Susceptibility of International and Austrian Wheat Breeding Material. Die Bodenkultur, 44, 65-78. 
[38] Lemmens, M., Krska, R., Buerstmayr, H., Josephs, R., Schuhmacher, R., Grausgruber, H. and Ruckenbauer, P. (2003) Fusarium Head Blight Reactions and Accumulation of Deoxynivalenol, Moniliformin and Zearalenone in Wheat Grains. Cereal Research Communications, 31, 407-414.

[39] Lemmens, M., Buerstmayr, H., Krska, R., Schuhmacher, R., Grausgruber, H. and Ruckenbauer, P. (2004) The Effect of Inoculation Treatment and Long-Term Application of Moisture on Fusarium Head Blight Symptoms and Deoxynivalenol Contamination in Wheat Grains. European Journal of Plant Pathology, 110, 299-308. http://dx.doi.org/10.1023/B:EJPP.0000019801.89902.2a

[40] Miedaner, T. (1997) Breeding Wheat and Rye for Resistance to Fusarium Diseases. Plant Breeding, 116, $201-220$. http://dx.doi.org/10.1111/j.1439-0523.1997.tb00985.x

[41] Ma, H.X., Zhanga, K.M., Gaoa, L., Baib, G.H., Chena, H.G., Caia, Z.X. and Lua, W.Z. (2006) Quantitative Trait Loci for Resistance to Fusarium Head Blight and Deoxynivalenol Accumulation in Wangshuibai Wheat under Field Conditions. Plant Pathology, 55,739-745. http://dx.doi.org/10.1111/j.1365-3059.2006.01447.x

[42] Jin, F., Dadong, Z., Bockus, W., Baenziger, P.S., Carver, B. and Bai, G.-H. (2013) Fusarium Head Blight Resistance in U.S. Winter Wheat Cultivars and Elite Breeding Lines. Crop Science, 53, 2006-2013. http://dx.doi.org/10.2135/cropsci2012.09.0531

[43] Mesterházy, Á. (1977) The Effect of Inoculation Method on the Expression of Symptoms Caused by Fusarium graminearum Schwabe on Wheat in Seedling Stage. Current Topics in Plant Pathology, 1975, issued 1977, Akad. Kiadó, 223-232.

[44] Mesterházy, Á. (2002) Role of Deoxynivalenol in Aggressiveness of Fusarium graminearum and F. culmorum and in Resistance to Fusarium Head Blight. European Journal of Plant Pathology, 108, 675-684. http://dx.doi.org/10.1023/A:1020631114063

[45] van Eeuwijk, E.A., Mesterhazy, A., Kling, Ch.I., Ruckenbauer, P., Saur, L., Buerstmayr, H., Lemmens, M., Keizer, L.C.P., Maurin, N. and Snijders, C.H.A. (1995) Assessing Non-Specificity of Resistance of Fusarium culmorum, F. graminearum and F. nivale using a Multiplicative Model for Interaction. Theoretical and Applied Genetics, 90, 221-228. http://dx.doi.org/10.1007/BF00222205

[46] Snijders, C.H.A. (1990) Genetic-Variation for Resistance to Fusarium Head Blight in Bread Wheat. Euphytica, 50, 171-179. http://dx.doi.org/10.1007/BF00023642

[47] Brown-Guedira, G., Griffey, C., Kolf, F., McKendry, A., Murphy, J.P. and van Sanford, D. (2008) Breeding FHB-Resistant Soft Winter Wheat: Progress and Prospects. Cereal Research Communications, 36, 31-36. http://dx.doi.org/10.1556/crc.36.2008.suppl.b.5

[48] Martinez-Espinoza, A., Ethredge, R., Youmans, V., John, B. and Buck, J. (2014) Identification and Control of Fusarium Head Blight (Scab) of Wheat in Georgia. http://extension.uga.edu/publications/files/pdf/C\%201066_1.PDF

[49] Mesterházy, Á. (1984) A Laboratory Method to Predict Pathogenicity of Fusarium graminearum in Field and Resistance to Scab. Acta Phytopathologica Academiae Scientiarum Hungaricae, 19, 205-218.

[50] Atanasoff, D. (1920) Fusarium Blight (Scab) of Wheat and Other Cereals. Journal of Agricultural Research, 20, 1-32.

[51] Rudd, J.C., Horsley, R.D., McKendry, A.L. and Elias, E.M. (2001) Host Plant Resistance Genes for Fusarium Head Blight: Sources, Mechanisms, and Utility in Conventional Breeding Systems. Crop Science, 41, 620-627. http://dx.doi.org/10.2135/cropsci2001.413620x

[52] Stack, R.W., Frohberg, R.C. and Casper, H. (1997) Reaction of Spring Wheats Incorporating Sumai\#3-Derived Resistance to Inoculation with Several Fusarium Species. Cereal Research Communications, 25, 667-671.

[53] Mesterházy, Á. (1985) Effect of Seed Production Area on the Seedling Resistance of Wheat to Fusarium Seedling Blight. Agronomie, 5, 491-497. http://dx.doi.org/10.1051/agro:19850604

[54] Grausgruber, H., Lemmens, M., Bürstmayr, H. and Ruckenbauer, P. (1995) Evaluation of Inoculation Methods for Testing Fusarium Head Blight Resistance of Winter Wheat on Single Plant Basis. Bodenkultur, 46, 39-49.

[55] de Villiers, C.I.P. (2009) A Comparison of Screening Techniques for Fusarium Head Blight of Wheat in South Africa. MS Thesis, University of the Free State, Bloemfontein, 108 p.

[56] Thomson, C.J. (2010) Evaluation of an Inoculation Method and Quantitative Trait Loci for Fusarium Head Blight Resistance in Wheat. MS Thesis, University of Illinois at Urbana-Champaign, Champaign-Urbana, 108 p.

[57] Jalaluddin, M.D. and Harrison, S.A. (1993) Repeatability of Stability Estimators for Grain Yield in Wheat. Crop Science, 33, 720-725. http://dx.doi.org/10.2135/cropsci1993.0011183X003300040017x

[58] Eberhart, S.A. and Russel, W.A. (1966) Stability Parameters for Comparing Parameters. Crop Science, 6, 36-40. http://dx.doi.org/10.2135/cropsci1966.0011183X000600010011x

[59] Sváb, J. (1981) Biometriai Módszerek a Kutatásban (Methods for Biometrics in Research). 3rd Edition, Mezőgazdasági Kiadó (Agr. Publ. House), Budapest, 1-557. 
[60] Weber, E. (1967) Grundriss der BiologischenStatistik (Fundaments of the Biological Statistics). VEB Fisher Verlag, Jena.

[61] Holzapfel, J., Voss, H.-H., Miedaner, T., Korzun, V., Häberle, J., Schweizer, G., Mohler, V., Zimmermann, G. and Hartl, L. (2008) Inheritance of Resistance to Fusarium Head Blight in Three European Winter Wheat Populations. Theoretical and Applied Genetics, 117, 1119-1128. http://dx.doi.org/10.1007/s00122-008-0850-z

[62] Kubo, K., Kawada, N., Nakajima, T., Hirayae, K. and Fujita, M. (2014) Field Evaluation of Resistance to Kernel Infection and Mycotoxin Accumulation Caused by Fusarium Head Blight in Western Japanese Wheat (Triticum aestivum L.) Cultivars. Euphytica, 200, 81-93. http://dx.doi.org/10.1007/s10681-014-1148-7

[63] Gärtner, B.H., Munich, M. and Mascher, F.N. (2008) Characterization of Kernel Resistance against Fusarium Infection in Spring Wheat by Baking Quality and Mycotoxin Assessments. European Journal of Plant Pathology, 120, 61-68. http://dx.doi.org/10.1007/s10658-007-9198-5

[64] Sneller, C., Guttieri, M., Paul, P., Costa, J. and Jackwood, R. (2012) Variation for Resistance to Kernel Infection and Toxin Accumulation in Winter Wheat Infected with Fusarium graminearum. Phytopathology, 102, 306-314. http://dx.doi.org/10.1094/PHYTO-05-11-0143

[65] Anonymous (2015) Fusarium Head Blight. Government of Saskatchewan. http://www.agriculture.gov.sk.ca/fusarium-head-blight

[66] Wegulo, S., Jackson, T.A., Baenziger, P.S., Carlson, M.P. and Nopsa, J.H. (2008) Fusarium Head Blight of Wheat. University of Nebraska Lincoln, Extension. http://ianrpubs.unl.edu/live/ec1896/build/ec1896.pdf

[67] Miller, J.D. and Melvin, A.E. (1997) Toxic Effects of Deoxynivalenol on Ribosomes and Tissues of the Spring Wheat Cultivars Frontana and Casavant. Natural Toxins, 5, 234-237. http://dx.doi.org/10.1002/(SICI)1522-7189(1997)5:6<234::AID-NT3>3.0.CO;2-Q

[68] Wilde, F., Korzun, V., Ebmeyer, E., Geiger, H.H. and Miedaner, T. (2007) Comparison of Phenotypic and MarkerBased Selection for Fusarium Head Blight Resistance and DON Content in Spring Wheat. Molecular Breeding, 19, 357-370. http://dx.doi.org/10.1007/s11032-006-9067-5

[69] Wilde, F., Schön, C.C., Korzun, V., Ebmeyer, E., Schmolke, M., Hartl, L. and Miedaner T. (2008) Marker-Based Introduction of Three Quantitative-Trait Loci Conferring Resistance to Fusarium Head Blight into an Independent Elite Winter Wheat Breeding Population. Theoretical and Applied Genetics, 117, 29-35. http://dx.doi.org/10.1007/s00122-008-0749-8

[70] Yang, Z. (1994) Breeding Resistance to Fusarium Head Blight of Wheat in the Mid- to Lower Yangtze River Valley of China. CIMMYT Wheat Special Report No. 27, 16 p.

[71] Steiner, B., Lemmens, M., Griesser, M., Scholz, U., Schondelmaier, J. and Buerstmayr, H. (2004) Molecular Mapping of Resistance to Fusarium Head Blight in the Spring Wheat Cultivar Frontana. Theoretical and Applied Genetics, 109, 215-224. http://dx.doi.org/10.1007/s00122-004-1620-1

[72] Tóth, B., Kászonyi, G., Bartók, T., Varga, J. and Mesterházy, Á. (2008) Common Resistance of Wheat to Members of the Fusarium graminearum Species Complex and F. culmorum. Plant Breeding, 127, 1-8. http://dx.doi.org/10.1111/j.1439-0523.2008.01412.x

[73] Mesterházy, Á. (1997) Methodology of Resistance Testing and Breeding against Fusarium Head Blight in Wheat and Results of Selection. Cereal Research Communications, 25, 631-637. 